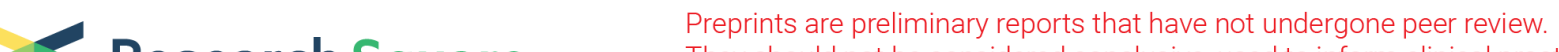 Research Square They should not be considered conclusive, used to inform clinical practice, or referenced by the media as validated information.
}

\section{A potent and protective human neutralizing antibody targeting a key vulnerable site of Epstein-Barr Virus}

Qian-Ying Zhu

Sun Yat-sen University

\section{Sisi Shan}

Tsinghua University https://orcid.org/0000-0002-7184-6818

\section{Jinfang $Y u$}

Tsinghua University https://orcid.org/0000-0002-2294-0752

\section{Si-Ying Peng}

Bejing IDMO Company Limited

\section{Cong Sun}

Sun Yat-sen University Cancer Center

Yanan Zuo

School of Medicine, Tsinghua University

Shu-Mei Yan

Sun Yat-Sen University Cancer Center

\section{Xiao Zhang}

Sun Yat-sen University Cancer Center

\section{Ziqing Yang}

Tsinghua University

Lan-Yi Zhong

Sun Yat-sen University

\section{Xuangling Shi}

Tsinghua University

\section{Su-Mei Cao}

Sun Yat-sen University Cancer Center

\section{Xinquan Wang}

Tsinghua University https://orcid.org/0000-0003-3136-8070

\section{Mu-Sheng Zeng}

Sun Yat-sen University Cancer Center https://orcid.org/0000-0003-3509-5591

Linqi Zhang ( $\square$ zhanglinqi@tsinghua.edu.cn )

Tsinghua University https://orcid.org/0000-0003-4931-509X 
Keywords: EBV, human neutralizing antibody, humanized mouse model, epitope

Posted Date: January 25th, 2021

DOl: https://doi.org/10.21203/rs.3.rs-151895/v1

License: (c) (1) This work is licensed under a Creative Commons Attribution 4.0 International License. Read Full License

Version of Record: A version of this preprint was published at Nature Communications on November 16th, 2021. See the published version at https://doi.org/10.1038/s41467-021-26912-6. 


\section{A potent and protective human neutralizing antibody targeting a key} vulnerable site of Epstein-Barr Virus

Qian-Ying Zhu ${ }^{1,6}$, Sisi Shan ${ }^{2,6}$, Jinfang Yu ${ }^{3,6}$, Si-Ying Peng ${ }^{5}$, Cong Sun ${ }^{1}$, Yanan Zuo $^{2}$, Shu-Mei Yan ${ }^{1}$, Xiao Zhang ${ }^{1}$, Ziqing Yang ${ }^{2}$, Lan-Yi Zhong ${ }^{1}$, Xuanling Shi ${ }^{2}$, Su-Mei $\mathrm{CaO}^{4}$, Xinquan Wang ${ }^{3,{ }^{*}}$, Mu-Sheng Zeng ${ }^{1,{ }^{*},}$, Linqi Zhang ${ }^{2,7,{ }^{*}}$

${ }^{1}$ State Key Laboratory of Oncology in South China, Collaborative Innovation Center for Cancer Medicine, Guangdong Key Laboratory of Nasopharyngeal Carcinoma Diagnosis and Therapy, Sun Yat-sen University Cancer Center (SYSUCC), Guangzhou 510060, China.

${ }^{2}$ Comprehensive AIDS Research Center, and Beijing Advanced Innovation Center for Structural Biology, School of Medicine and Vanke School of Public Health, Tsinghua University, Beijing 100084, China.

${ }^{3}$ The Ministry of Education Key Laboratory of Protein Science, Beijing Advanced Innovation Center for Structural Biology, Beijing Frontier Research Center for Biological Structure, Collaborative Innovation Center for Biotherapy, School of Life Sciences, Tsinghua University, 100084 Beijing, China.

${ }^{4}$ State Key Laboratory of Oncology in South China, Department of Cancer Prevention Research, Sun Yat-sen University Cancer Center (SYSUCC), Guangzhou 510060, China.

${ }^{5}$ Bejing IDMO Company Limited, Beijing, China.

${ }^{6}$ These authors contributed equally to this work.

${ }^{7}$ Lead Contact

"Correspondence:

xinquanwang@mail.tsinghua.edu.cn;

zengmsh@sysucc.org.cn;

zhanglinqi@mail.tsinghua.edu.cn 


\section{ABSTRACT}

Epstein-Barr virus (EBV) is associated with a range of epithelial and $B$ cell malignancies as well as autoimmune disorders, for which there are still no specific treatments or effective vaccines. Here, we isolated EBV $\mathrm{gH} / \mathrm{gL}$-specific antibodies from an EBV-infected individual. One antibody, 1D8, efficiently neutralized EBV infection of two major target cell types, B cells and epithelial cells. In humanized mice, 1D8 provided strong protection against a high-dose EBV challenge by substantially reducing viral loads and associated tumor burden. Crystal structure analysis revealed that 1D8 binds to a key vulnerable interface between the $\mathrm{D}-\mathrm{I} / \mathrm{D}-\mathrm{II}$ domains of the viral $\mathrm{gH} / \mathrm{gL}$ protein, especially the D-II of the $\mathrm{gH}$, thereby interfering with the $\mathrm{gH} / \mathrm{gL}$-mediated membrane fusion and binding to target cells. Overall, we identified a potent neutralizing antibody as a promising candidate for prophylactic and therapeutic interventions against EBV infection. The key vulnerable site also provides insights into the EBV vaccines design.

KEY WORDS: EBV, human neutralizing antibody, humanized mouse model, epitope 


\section{INTRODUCTION}

Epstein-Barr virus (EBV) is the causative agent of a wide range of diseases

in humans such as infectious mononucleosis and lymphoproliferative disorders, as well as epithelial and B cell malignancies including nasopharyngeal carcinoma and Burkitt's lymphoma(1-4). Despite decades of research, a safe and effectively vaccine against EBV still remains elusive, largely due to a lack of knowledge regarding the specificity and magnitude of immune responses required for protection(5-8). EBV-infected individuals produce broad and potent neutralizing antibodies that can inhibit infection of both epithelial cells and $B$ cells in vitro(9-13). However, their specificity to viral antigens and potential mechanism of neutralization are not clear.

Recent studies on monoclonal antibodies (mAbs) revealed some of the intricate interactions between antibodies and viral surface antigens, providing critical insights into the potential targets for antibody neutralization and vaccine development(14-18). The reported mAbs recognize exclusively viral surface glycoproteins that work in concert in determining viral tropism and mediating viral fusion with the target cells, such as $\mathrm{gp} 350, \mathrm{gH} / \mathrm{gL}, \mathrm{gB}$ and $\mathrm{gp} 42(19-22)$. Recently, $\mathrm{gH} / \mathrm{gL}$ and $\mathrm{gB}$, which together constitute the fusion machinery of EBV, have drawn increasing attention as newer generations of antibodies targeting this machinery demonstrate broad and potent inhibitory activity against EBV infection of both B cells and epithelial cells(23), as well as cross-neutralizing reactivity to related herpesviruses of non-human primate $(9,24,25)$. 
As components of the fusion machinery, $\mathrm{gH} / \mathrm{gL}$ and $\mathrm{gB}$ demonstrate unique structural and functional features that are critical for viral entry, but they also inadvertently expose some vulnerable sites during the process, and became susceptible to antibody binding and neutralization(26-28). Structurally, $\mathrm{gH} / \mathrm{gL}$ consists of four distinct domains named domain-I (D-I) to domain-IV (D-IV), forming an elongated structure(29). D-I is formed by $\mathrm{gL}$ and the $\mathrm{N}$-terminus of $\mathrm{gH}$, while D-II to D-IV are formed by the rest of $\mathrm{gH}$. D-I and D-II are connected through a linker helix and form a structurally distinct groove. For viral fusion to occur, $\mathrm{gH} / \mathrm{gL}$ must interact with $\mathrm{gB}$, which triggers a cascade of events involving dramatic structural changes of $\mathrm{gB}$ from the pre- to the post-fusion conformation $(27,28)$. Mutations in the D-I and D-I/D-II interfaces of $\mathrm{gH} / \mathrm{gL}$ were shown to affect the membrane fusion process, suggesting that these regions of $\mathrm{gH} / \mathrm{gL}$ are important for the interaction and activation of $\mathrm{gB}(30,31)$.

Apart from the fusion machinery, EBV infection requires additional surface glycoproteins to complete the entry process, but the involved accessory molecules are rather different between B cells and epithelial cells(32). For instance, EBV utilizes gp350, one of the most abundant glycoproteins on the viral envelope, to attach to the cell surface through high-affinity interaction with CD21 or CD35(33-35). Such attachment promotes the bridging effect of another surface glycoprotein, gp42, which inserts itself between $\mathrm{gH} / \mathrm{gL}$ and human leukocyte antigen (HLA) class II, which triggers the downstream fusion machinery (36, 37). Interestingly, gp42 has an inhibitory effect on epithelial cell 
infection, suggesting a different entry mechanism in B cells and epithelial cells(38). For infection of epithelial cells, $\mathrm{gH} / \mathrm{gL}$ first binds to integrin and NMHC-IIA on the cell surface. The fusion machinery then interacts with neuropilin 1 (NRP1) and ephrin receptor A2 (EphA2)(39-41), which leads to a conformational transition of $\mathrm{gB}$, facilitating viral fusion $(27,42)$.

Most of the current anti-gH/gL antibodies are of murine origin(36, 43). E1D1, CL59 and CL40 can block epithelial cell infection but fail to efficiently neutralize B cell infection(22). Only one human neutralizing antibody targeting $\mathrm{gH} / \mathrm{gL}$, AMMO1, was recently isolated from an EBV-infected individual(22). AMMO1 can potently block infection of both B cells and epithelial cells in vitro. AMMO1 can also protect humanized mice from EBV challenge and provide sterilizing immunity in macaques against oral challenge with rhesus lymphocryptovirus, the EBV relative that infects rhesus macaques. These findings indicate that a vaccine capable of inducing AMMO1-like neutralizing antibodies may protect human from EBV infection. Cryo-electron microscopy (cryoEM) analysis of the AMMO1-gH/gL-gp42 complex revealed that AMMO1 binds to an epitope between $\mathrm{D}-\mathrm{I}$ and $\mathrm{D}-\mathrm{II}$ of $\mathrm{gH} / \mathrm{gL}(22)$, which serves as a more precise and clear target for future vaccine design and development. Here, we sought to isolate more neutralizing antibodies from EBV-infected individuals targeting the $\mathrm{EBV} \mathrm{gH} / \mathrm{gL}$. After screening a large number of infected individuals, we successfully isolated the anti-gH/gL antibody $1 \mathrm{D} 8$, which is capable of efficiently neutralizing EBV infection of epithelial cells and B cells in 
vitro. 1D8 also provided potent protection against EBV challenge in humanized mice by significantly reducing the viral loads and associated tumor burden. Using X-ray crystallography, we determined the structure of the $1 \mathrm{D} 8-\mathrm{gH} / \mathrm{gL}$ complex and showed that 1D8 recognizes a key epitope located at the top of the groove between $\mathrm{D}-\mathrm{I}$ and $\mathrm{D}-\mathrm{II}$ of $\mathrm{gH} / \mathrm{gL}$, especially the $\mathrm{D}-\mathrm{Il}$ of $\mathrm{gH}$. Notably, this epitope is located on the opposite side of that recognized by AMMO1 and CL40. In addition, 1D8 also significantly inhibited viral membrane fusion and $\mathrm{gH} / \mathrm{gL}$ binding to epithelial cell receptor EphA2. We believe that this new vulnerable site, together with that recognized by AMMO1 and CL40, suggests that D-I and D-II represent an attractive target for the rational design of vaccines aiming to elicit antibody responses similar to these mAbs. Finally, 1D8 could also be used alone or in combination with other mAbs in prophylactic and therapeutic interventions against EBV infection either in organ transplant recipients or immunocompromised patients.

\section{RESULTS}

\section{Isolation of human monoclonal antibodies targeting the EBV $\mathrm{gH} / \mathrm{gL}$}

We first screened plasma samples from a cohort of high-risk individuals and nasopharyngeal carcinoma patients $(44,45)$ for those with the highest levels of binding and neutralizing activity. Of the 48 plasma samples screened, donor 27 from the high-risk group had antibodies with the highest affinity for $\mathrm{gH} / \mathrm{gL}$ measured by ELISA, with the half-maximal effective concentration (EC50) 
corresponding to a 6874 -fold dilution (fig. S1A). The same plasma sample also displayed the most potent neutralizing activity against EBV infection of HNE1 epithelial cells and Raji B cells, with respective half-maximal inhibitory concentrations (IC50) corresponding to a 273 -fold and 1250-fold dilution (fig. S1B). To isolate monoclonal antibodies, we used phycoerythrin (PE) conjugated $\mathrm{gH} / \mathrm{gL}$ as baits to stain and sort the antigen-specific memory B cells from the peripheral blood mononuclear cells (PBMCs) of donor 27 using flow cytometry (Fig. 1A). Out of a total 54 sorted single B cells, we were able to clone and express 10 full-length human immunoglobulin G1 (IgG1) genes in transfected 293T cells. Two antibodies, 1D8 and 2A6, were found to have strong binding to $\mathrm{gH} / \mathrm{gL}$. As shown in Fig. 1B, 1D8 showed $\sim 7$-fold stronger binding to $\mathrm{gH} / \mathrm{gL}$ than $2 \mathrm{~A} 6$, with an EC50 of $0.008 \mu \mathrm{g} / \mathrm{ml}$ and $0.057 \mu \mathrm{g} / \mathrm{ml}$, respectively. 1D8 also demonstrated higher neutralizing activity than 2A6 against EBV infection of HNE1 epithelial cells and Raji B cells (Fig. 1C,D and table S1). The $\mathrm{IC}_{50}$ of $1 \mathrm{D} 8$ was about 6 times lower than that of $2 \mathrm{~A} 6$ for both cell types. Notably, 1D8 displayed comparable binding and neutralizing activities to $\mathrm{AMMO1}$, a potent $\mathrm{gH} / \mathrm{gL}$-specific neutralizing antibody previously isolated from an EBV-infected individual(22). The equilibrium dissociation constant (KD) measured by SPR was $0.59 \mathrm{nM}$ for $1 \mathrm{D} 8$ and $0.14 \mathrm{nM}$ for AMMO1 (fig. S1C,D and table S2). When tested for neutralizing activity against EBV infection, 1D8 and AMMO1 showed IC50 values of 0.238 and $0.318 \mu \mathrm{g} / \mathrm{ml}$ in Raji B cells, as well as 0.123 and $0.127 \mu \mathrm{g} / \mathrm{ml}$ in HNE1 epithelial cells, 
respectively (Fig. 1C,D and table S1).

\section{D8 protects against lethal EBV challenge in humanized mice}

To test the protective potential of 1D8 in vivo, we used a humanized mouse model reconstituted with human cord blood-derived CD34+ stem cells that became susceptible to EBV infection and disease after approximately 8 weeks of development and maturation(46-48). The entire experimental protocol and assays conducted to evaluate protection are outlined in Fig. 2A. Briefly, we administrated $400 \mu \mathrm{g}$ of $1 \mathrm{D} 8, \mathrm{AMMO} 1$ as positive control, or $2 \mathrm{G} 4$ and PBS as negative controls to groups of seven to eight humanized mice via the intraperitoneal (i.p.) route. On the following day, the animals were challenged with $1,00050 \%$ transforming dose $\left(\mathrm{TD}_{50}\right)$ Akata $\mathrm{EBV}$ via the intravenous (i.v.) route. In the ensuing up to 6 -week period, all animals received the testing antibodies or PBS weekly via the i.p. route and were monitored for body weight, survival, as well as various virological and immunological parameters.

EBV DNA in the peripheral blood measured by quantitative PCR reflected the distinctions in clinical manifestation between these animals (Fig. 2B). In the animals treated with 1D8 and AMMO1, EBV DNA became detectable on week 3 after challenge and slowly increased in the following two weeks, but no animals had EBV DNA copy numbers greater than 10 copies $/ \mu$ l blood at week 5 post challenge. By contrast, in the animals treated with 2G4 and PBS, EBV DNA rapidly increased from week 3 onwards after the challenge and reached 
181

182

about 100-fold higher copy numbers than in the groups treated with 1D8 and AMMO1 at week 5 post-challenge (Fig. 2B). All animals in the 1D8 and AMMO1 treated groups survived the challenge and demonstrated relatively stable body weight without obvious pathology (Fig. 2C,D). By contrast, negative control animals (2G4 and PBS groups) began significantly losing weight starting on day 28 (4 weeks), succumbed to disease and had to be euthanized by day 38 after the challenge.

By the time they were ready for the protection experiments, the reconstituted animals had about $20 \%$ human CD45+ lymphocytes in the peripheral blood, nearly $90 \%$ of which were human CD20+ B cells and $<1 \%$ were human CD3+ T cells (Fig. 2E-G). In addition, the dynamic change of human CD20+ B cells and CD3+ T cells in the peripheral blood was correlated with distinct pattern of disease progression between these animals. Animals in the 1D8 and AMMO1 treated groups showed a relatively slower decrease in the number of CD20+ B cells compared with the $2 \mathrm{G} 4$ and PBS treated groups. At the same time, the increase in the number of CD3+ T cells was slower in animals treated with 1D8 and AMMO1 compared to those treated by $2 \mathrm{G} 4$ and PBS (Fig. 2F,G).

Furthermore, EBV DNA copy numbers measured in the spleen, liver and kidney collected at necropsy shared a similar trend with those measured in the peripheral blood (Fig. $2 \mathrm{H}, \mathrm{J})$. The copy numbers of EBV DNA were significantly lower in the 1D8 and AMMO1 treated groups than in the 2G4 and PBS treated groups, although the copy numbers were generally higher in the spleen than in 
the liver and kidney (Fig. 2H,J). Taken together, these results demonstrated that $1 \mathrm{D} 8$ as well as the positive control AMMO1 can significantly reduce viral replication and provide complete protection from a lethal EBV challenge.

\section{Marked reduction in viral replication and tissue damages in the protected} animals

To study the impact of protection at the tissue levels, we collected the spleen, liver and kidney of the animals at the necropsy. The most profound and visible changes were observed in the spleens. Morphologically, the spleens from the 2G4 and PBS groups were clearly enlarged with a few irregular and pale tumors across the entire surface. By contrast, the spleens in the 1D8 and AMMO1 groups were normal in size and color, without visible tumors (Fig. 3). We went on to perform histopathology analysis on the spleen sections using hematoxylin and eosin (H\&E) staining, immunohistochemistry (IHC) for hCD3 and hCD20, as well as in situ hybridization for Epstein-Barr virus-encoded RNAs (EBERs) (Fig. 3). All mice treated with 2G4 or PBS presented with typically large B-cell lymphomas in the white pulp regions, which consisted of large and atypical lymphoid cells that were positive for hCD20 and EBER. They were abundant and widely distributed across the tissue sections. Morphologically their proliferations destroyed the underlying architecture of the tissue with some infiltration by $\mathrm{hCD} 3+\mathrm{T}$ cells. Additionally, areas of coagulative necrosis were often present in the spleens of mice from the $2 \mathrm{G} 4$ 
and PBS groups. By contrast, in the 1D8 and AMMO1 groups, the overall tissue architecture remained largely intact, even if some atypical large transformed cells could also be seen. Among the large number of hCD20+ B cells in the white pulp areas, EBER+ cells were relatively scarce. A few hCD3+ T cells were also found scattered within. Similarly, in the hepatic and renal sections from 2G4 and PBS groups, a large number of hCD20+ and EBER+ $B$ cells were identified, while they were rare in the 1D8 and AMMO1 groups (fig. S2). The infected cells were frequently found near the blood vessels in both the liver and kidney, likely the results of migration and seeding from the blood circulation. Collectively, these results show that 1D8 and AMMO1 can significantly reduce viral replication and tissue damage relative to $2 \mathrm{G} 4$ and PBS, offering an explanation for their impressive in vivo protection against a lethal EBV challenge.

\section{$1 \mathrm{D} 8$ binds to a key epitope on $\mathrm{gH} / \mathrm{gL}$}

To understand the neutralizing mechanism of $1 \mathrm{D} 8$, we sought to determine the structure of the $1 \mathrm{D} 8-\mathrm{gH} / \mathrm{gL}$ complex by $\mathrm{X}$-ray crystallography. After screening nearly 100 crystals with relatively weak diffraction, we obtained a dataset with $4.2 \AA$ resolution and solved the structure by molecular replacement (table S3). The structure showed that 1D8 bound to the interface at the top of the groove formed by $\mathrm{D}-\mathrm{I}$ and $\mathrm{D}-\mathrm{II}$ of $\mathrm{gH} / \mathrm{gL}$, especially the D-II of $\mathrm{gH}$ (Fig. 4A). $1 \mathrm{D} 8$ bound to the unique epitope spanning of $\mathrm{gH} / \mathrm{gL}$, which comprised residues of both $\mathrm{gH}$ 
and gL, burying a surface area of $969 \AA^{2}$. CDRL1, CDRL3 and CDRH2 of 1D8 made practically no contribution to the binding of $\mathrm{gH} / \mathrm{gL}$. CDRL2 mainly bound to $2 \alpha-2$ and $2 \beta-2$. The loop between $2 \alpha-9$ and $2 \beta-11$ was bound by $\mathrm{CDRH} 1$ and CDRH3. CDRH3 also bound to the loop between $2 \alpha-1$ and $2 \beta-1$. The heavy chain of $1 \mathrm{D} 8$ bound to the loop between La-1 and La-2 (Fig. 4B). To identify the key residue for antibody binding, we generated a series of single alanine substitutions for the contacting residues on $\mathrm{gH} / \mathrm{gL}$. Except for two (L122A and C312A), the remaining 15 mutants were successfully expressed and purified from the supernatant of transfected 293F cells. We then performed ELISA to assess the impact of these mutants on 1D8 binding. One mutant, N310A, locate in the loop between $2 \alpha-9$ and $2 \beta-11$, was identified to specifically reduce the binding of 1D8 but not AMMO1 (Fig. 4B and fig. S3A,B). When measured by SPR, the binding affinity of 1D8 for this particular mutant dropped to $31.6 \mathrm{nM}$, representing more than 53-fold decrease compared to the wild type $\mathrm{gH} / \mathrm{gL}$. However, no significant change of binding was found for AMMO1 compared to the wild type $\mathrm{gH} / \mathrm{gL}$ (fig. S3C,D and table S2). The unique binding of $1 \mathrm{D} 8$ is further supported by superimposing the antibodies with known structural information onto the same $\mathrm{gH} / \mathrm{gL}$ molecule. As shown in Fig. 4C,D, 1D8 bound to $\mathrm{gH} / \mathrm{gL}$ at the top of the groove formed between D-I and $\mathrm{D}-\mathrm{II}$, especially the $\mathrm{D}-\mathrm{II}$ of $\mathrm{gH}$, while AMMO1 binds the opposite side of the molecule through a discontinuous epitope formed at the D-I/D-II interface. The mouse-derived antibody CL40 partially overlaps with the epitope of AMMO1 by 
binding to an epitope on $\mathrm{gH}$ at the interface between $\mathrm{D}-\mathrm{II}$ and $\mathrm{D}-\mathrm{III}(22)$.

270 Another mouse antibody E1D1, however, only recognizes gL(36, 43) (Fig.

$2714 \mathrm{C}, \mathrm{D})$. We also used bio-layer interferometry (BLI) to confirm that 1D8 does

272 not compete with any of these antibodies in binding to $\mathrm{gH} / \mathrm{gL}$ (fig. S3E). These

273 results indicate that $1 \mathrm{D} 8$ recognizes a key vulnerable site on $\mathrm{gH} / \mathrm{gL}$ and

274 provide a good rational basis for combined use with other antibodies in 275 suppressing EBV infection.

1D8 inhibits $\mathrm{gH} / \mathrm{gL}-$-mediated membrane fusion and binding to $\mathrm{B}$ and epithelial cells

We next studied the ability of $1 \mathrm{D} 8$ to inhibit $\mathrm{gH} / \mathrm{gL}$ mediated membrane fusion

by monitoring the fusion efficiency between the effector and target cells.

281

282

Specifically, effector $\mathrm{CHO}-\mathrm{K} 1$ cells expressing the $\mathrm{gH} / \mathrm{gL}$ and $\mathrm{gB}$ fusion machinery were incubated with a saturated concentration of 1D8 or relevant controls at $37^{\circ} \mathrm{C}$ for $1 \mathrm{~h}$ before mixing at a $1: 1$ ratio with the target HEK293 cells. The inhibitory activity was measured $24 \mathrm{~h}$ afterwards via the luciferase activity in the cell lysates, which only became detectable when fusion occurred. As shown in Fig. 5A-C, the effector CHO-K1 cells expressed good levels of $\mathrm{gH} / \mathrm{gL}$ as measured by flow cytometry. In the presence of $1 \mathrm{D} 8$ or AMMO1, the fusion activity was barely measurable and similar to the background where only the effector cells were present (Fig. 5D). By contrast, incubation with the negative controls 2G4 or PBS resulted in high levels of luciferase activity 
291

292

beyond one million relative light unit (RLU). In addition, we tested the ability of 1D8 to interfere with the binding of fluorescently labelled $\mathrm{gH} / \mathrm{gL}$ to Raji $B$ cells and HK1 epithelial cells, both of which are susceptible to EBV infection in vitro $(49,50)$. Gp42 was included in the assessment of the binding to B cells but not for the epithelial cells, since the $\mathrm{gH} / \mathrm{gL}-\mathrm{gp} 42$ complex is specifically required for B cell activation and fusion(36). 1D8 and relevant controls were incubated with fluorescent-labeled $\mathrm{gH} / \mathrm{gL}$ at $37^{\circ} \mathrm{C}$ for $1 \mathrm{~h}$ before mixing with $\mathrm{B}$ cells or epithelia cells and further incubation on ice for $1 \mathrm{~h}$. The levels of inhibition of $\mathrm{gH} / \mathrm{gL}$-mediated binding to both cell types were measured by flow cytometry. As shown in Fig. 5E, pre-incubation with 1D8 and AMMO1 significantly reduced but did not completely abrogate $\mathrm{gH} / \mathrm{gL}$-gp42 binding to $\mathrm{B}$ cells. While no difference was found between the negative controls 2G4 and PBS, AMMO1 appeared to be more potent than 1D8 in interfering with the binding of $\mathrm{gH} / \mathrm{gL}$ to $\mathrm{B}$ cells. Conversely, 1D8 seems to be more powerful than AMMO1 in inhibiting the binding of $\mathrm{gH} / \mathrm{gL}$ to the epithelia cells, whereas the negative controls showed negligible effect (Fig. 5F). Lastly, we studied the ability of $1 \mathrm{D} 8$ to inhibit the interaction between $\mathrm{gH} / \mathrm{gL}$ and EphA2, a recently identified receptor for EBV infection of epithelial cells that depends on an interaction with $\mathrm{gH} / \mathrm{gL}(39,40)$. Consistent with an earlier report(22), the interaction between EphA2-Fc and $\mathrm{gH} / \mathrm{gL}$ was indeed rather weak as measured by BLI. Nevertheless, pre-incubation of $\mathrm{gH} / \mathrm{gL}$ with $1 \mathrm{D} 8$ did result in a small and clear reduction in the interaction between $\mathrm{gH} / \mathrm{gL}$ and EphA2 (Fig. 
5G). Conversely, such an effect was not noticed for AMMO1 or 2G4 (Fig. 5H,I). This may explain why 1D8 was more effective than AMMO1 in inhibiting EBV infection of epithelial cells (see above), although the underlying mechanism warrants further investigation. Taken together, these findings indicate that 1D8 as well as the positive control AMMO1 can significantly inhibit $\mathrm{gH} / \mathrm{gL}$-mediated membrane fusion and binding to B and epithelial cells, either through direct blocking of binding or by sterically interfering with the downstream interactions required for EBV infection.

\section{DISCUSSION}

Neutralizing antibodies are the major component of protective immunity against viral infection in humans(51-53). They exert their function by targeting crucial epitopes on the viral envelope glycoproteins. Identifying the neutralizing mAbs and their recognized epitopes is therefore the first crucial step for understanding the protective antibody response, which can inform the rational development of antibody-based therapy and vaccines $(17,18)$. In some EBV-infected individuals, high levels of serum neutralizing antibodies have been identified capable of blocking infection of both B cells and epithelia cells(9). This finding indicates that the human immune system is able to generate potent neutralizing antibodies to clear the infection and/or attenuate disease progression. However, the antigen and epitope specificity, as well as the potential mechanism of neutralization of these antibodies are not entirely 
clear.

We report here the isolation and characterization of the human neutralizing antibody 1D8, which protects EBV infection in both B cells and epithelial cells. Passive delivery of 1D8 significantly reduced the viral loads and tumor burden of EBV-induced lymphoma in humanized mice. Structural analysis of the 1D8-gH/gL complex identified a key epitope at the top groove of $\mathrm{gH} / \mathrm{gL}$ between D-I and D-II, especially the D-II of $\mathrm{gH}$, which is distinct from any of the reported antibodies. In addition, 1D8 was found to inhibit viral membrane fusion and reduce the binding of $\mathrm{gH} / \mathrm{gL}$ to the epithelial cell receptor EphA2(39, 40). We believe that the new vulnerable site recognized by $1 \mathrm{D} 8$ represents another attractive target for the rational design of vaccines capable of eliciting 1D8-like neutralizing antibodies. 1D8 could also serve as a promising candidate for antibody-based therapy and prevention of EBV infection.

A couple of points need to be highlighted here. First, as both B cells and epithelia cells are major targets for EBV infection(54), it is highly desirable to isolate neutralizing antibodies capable of blocking the virus and protecting both cell types from infection. 1D8, together with recently reported AMMO1(22), are the only two representatives of this class of antibodies with dual tropism. However, we are uncertain how much this type of antibodies contributes to the overall neutralizing activities in the infected individuals. Given the low frequency in identifying 1D8 and AMMO1 antibodies among the isolated memory $B$ cells(22), it is reasonable to assume they are quite rare and might 
only be induced among a small proportion of naturally infected patients. Perhaps, this is due to the elusive nature of their epitopes, which are only transiently exposed during viral entry. It could also be due to their highly dynamic nature involving multiple conformational changes during infection. The rapid movement across the D-I and D-II groove required for binding and triggering of gB glycoprotein supports this notion $(30,31,55,56)$. Furthermore, compared to $\mathrm{gp} 350, \mathrm{gH} / \mathrm{gL}$ is much less abundant and therefore has a quantitative disadvantage in immune recognition and stimulation(19). However, identification of 1D8 and AMMO1 and their epitopes around D-I and D-II offer an unprecedented opportunity to expose this vulnerable site in much more precise and persistent manner so that more focused and stronger immune response like 1D8 and AMMO1 could be generated. This could be done either by including $\mathrm{gH} / \mathrm{gL}$ in the vaccine regimen $(9,23)$ or singling out $\mathrm{D}-\mathrm{I}$ and $\mathrm{D}-\mathrm{II}$ domain as epitope-focused immunogens. Both approaches would require careful design and validation to ensure proper structure and exposure of vulnerable sites recognized by $1 \mathrm{D} 8$ and AMMO1. In support of this notion, nanoparticles displaying $\mathrm{gH} / \mathrm{gL}$ elicited a strong neutralizing antibody response against EBV infection of both target cell types(9), even if this exciting report requires further confirmation. Lastly, given the relatively conserved nature of this region among herpesviruses $(24,27)$, carefully designed D-I and D-II immunogens may be able to induce an even broader and stronger cross-neutralizing antibody response against a wide variety of viral strains. 
Second, despite structural and functional insights, we are still not certain of the exact mechanism through which 1D8 neutralizes EBV infection of both target cell types. Structurally, 1D8 recognized a key epitope within the groove between D-I and D-II, especially the D-II of $\mathrm{gH}$, whereas AMMO1 was found to bind a discontinuous epitope spanning D-I and D-II on the opposite ridge of the groove(22). Such convergence on D-I and D-II domains suggests a common mechanism of neutralization, either by affecting coordination within and across D-I and D-II or their interaction with other viral glycoproteins such as gB or gp42 required for downstream viral entry (Fig. 6A,B). AMMO1 was postulated to lock D-I, D-II and the linker helix, preventing proper movement required for interaction and activation of $\mathrm{gB}(56)$. As residues with the $\mathrm{D}-\mathrm{I}$ and $\mathrm{D}-\mathrm{II}$ groove also mediate membrane fusion and several of these critical residues are near the epitope of $1 \mathrm{D} 8(30,31,55,56)$, it stands to reason that $1 \mathrm{D} 8$ could also exert its neutralization activity by inhibiting the fusion process. Instead of acting like a molecular clamp as AMMO1, 1D8 may act more like a molecular wedge forcing into the space within the groove. Certainly, as 1D8 and AMMO1 bind distinct epitopes, there must be some differences in the exact mechanisms underlying their inhibitory effects. For example, AMMO1 appears to be more potent than 1D8 in interfering with the binding of $\mathrm{gH} / \mathrm{gL}$ to $\mathrm{B}$ cells (Fig. $5 \mathrm{E}$ ), perhaps due to its ability to displace the c-terminal domain of gp42 through the gp42 N173 glycan(22). Conversely, 1D8 seems to be more powerful than AMMO1 in inhibiting binding of $\mathrm{gH} / \mathrm{gL}$ to epithelia cells, likely by affecting the 
401 interaction between EphA2-Fc and gH/gL (Fig. 5F,G and 6A). In any case, the 402 1D8 antibody identified in this study represents another potent human 403 neutralizing antibody that can be used alone or in combination with other 404 antibodies such as AMMO1 for antibody-based interventions against EBV 405 infection. The epitope defined here will also assist the rational design of 406 vaccines focusing more on the vulnerable sites to elicit powerful neutralizing 407 antibodies similar to 1D8 and AMMO1.

\section{MATERIALS AND METHODS}

\section{Human subjects}

411 We collected plasma samples from 48 participants including 23 histologically

412 diagnosed NPC cases and 25 non-NPC high-risk healthy controls in a screening program in Sihui County in Guangdong Province of China from 2007 and 2018. Peripheral blood mononuclear cell (PBMC) sample of donors 27 were collected in 2018. The screening program has been introduced in detail

416 in other manuscript. This study was reviewed and approved by the Ethics 417 Committee of the Sun Yat-Sen University Cancer Center (SYSUCC; 418 Guangzhou, Guangdong, China) and was conducted in accordance with the 419 Declaration of Helsinki.

Cell lines

All cell lines were cultured at $37^{\circ} \mathrm{C}$ in a humidified atmosphere comprising $5 \%$ 
423

424

425

$\mathrm{CO}_{2} .293 \mathrm{~T}$ cells $(\mathrm{ATCC})$ were grown in DMEM (GIBCO) $+10 \% \mathrm{FBS}(\mathrm{GIBCO})$. CHO K-1 cells (ATCC) were maintained in Ham's F-12 (GIBCO) $+10 \%$ FBS. Raji cells (ATCC), HNE1 cells(57) and HK1 cells(58) were maintained in RMPI1640+10\% FBS. Akata B cells(59) harboring a modified EBV, in which the thymidine kinase gene has been replaced with a neomycin and green fluorescence protein (GFP) cassette (Akata-GFP), were grown in RMPI 1640 (GIBCO) $+5 \%$ FBS. 293F cells (ThermoFisher) were maintained in Freestyle 293 medium (Union) with gentle shaking. All cells were grown with 100U/ml pencillin and $100 \mu \mathrm{g} / \mathrm{ml}$ streptomycin.

\section{Humanized mice}

The construction of the humanized mice was based on NOD.Cg-Prkdc ${ }^{\text {em11DMO }} / I 2 r g^{\text {em2IDMO }}$ mice (NOD-Prkdc null $\left.I L 2 R \gamma^{\text {null }}, N P I \circledast\right)(60)$, which were kept in a specific pathogen free (SPF) facility and obtained from BEIJING IDMO Co., Ltd. To generate the humanized immune system, mice were i.p. injected with a single dose of Busulfan at $20 \mathrm{mg} / \mathrm{kg}$ body weight. After 48h post-injection, the mice received an intravenous tail injection of human CD34+ cells, which were isolated from umbilical cord blood (Beijing Novay biotech) with a purity of over $90 \%$. Human CD45+ cells in peripheral blood of each humanized mouse were detected at 4 and 8 weeks post engraftment by flow cytometry. 


\section{Plasmids}

The $\mathrm{gH} / \mathrm{gL}$ [residues 19 to 679 of $\mathrm{gH}$ and residues 24 to 137 of $\mathrm{gL}$ were linked by $(\mathrm{G} 4 \mathrm{~S})_{3}$ ] and gp42 (residue 34 to 223 ) fragments were amplified from the bacterial artificial chromosome (BAC) of EBV-M81 by PCR and cloned into the pcDNA3.1 plasmid with an $\mathrm{N}$-terminal CD5 leader peptide and a $\mathrm{C}$-terminal HIS Tag. Targeted mutations were introduced into pcDNA3.1-CD5-gH/gL using the ClonExpress MultiS One Step Cloning Kit (Vazyme) and were confirmed by Sanger sequencing. The pCAGGS expression plasmids for $g \mathrm{H}, \mathrm{gL}, \mathrm{gB}$, and pT7EMCLuc (which carries a luciferase-containing reporter plasmid under the control of the T7 promoter) were kindly provided by Dr. R. Longnecker. The ectodomain of EphA2 was cloned in an Fc construct as described previously(61).

\section{Recombinant antibody cloning}

The $\mathrm{VH}$ and $\mathrm{VK} / \mathrm{V} \lambda$ genes of reference antibodies CL40, E1D1 and AMMO1 were obtained from PDB and codon optimized genes were synthesized by Tsingke Biological Technology Company. Antibody heavy chain and light chain variable gene fragments were obtained using separate primer pairs(62) with restriction enzyme cutting sites, including VH primers with 5'Agel and 3'Sall, VK primers with 5'Agel and 3'BsiWI, and V $\lambda$ primers with 5'Agel and 3'Xhol. Then PCR products were cloned into antibody expression vectors containing the constant regions of human IgG1. The sequences of the recombinant 
467

468

469

470

471

472

plasmids were verified by Sanger sequencing.

\section{Recombinant protein expression}

The 293F cells were transfected with plasmids encoding EBV glycoproteins, EphA2-Fc and recombinant antibodies at a density of $1.5 \times 10^{6} \mathrm{cells} / \mathrm{ml}$ in Freestyle 293 medium using PEI (Polysciences) transfection reagent according to the manufacturer's instructions. After five days, the culture supernatant containing EBV glycoprotein was collected and passed through Ni-NTA resin (GE Healthcare), followed by washing (PBS with 20mM imidazole, $\mathrm{pH7.4)}$ and elution (PBS with 250mM imidazole, $\mathrm{pH} 7.4$ ). The proteins were further purified by size exclusion chromatography (SEC) and dialyzed into PBS. Clarified cell supernatant containing recombinant antibodies or EphA2-Fc was passed over Protein A agarose (GenScript), followed by extensive washing with PBS, and then eluted with $10 \mathrm{~mL}$ of $0.3 \mathrm{M}$ glycine, $\mathrm{pH} 2.0$ into $1 \mathrm{~mL}$ of $1 \mathrm{M}$ Tris $\mathrm{HCl}, \mathrm{pH}$ 8.0. Purified proteins were then dialyzed into PBS.

\section{Recombinant protein biotinylation}

$\mathrm{gH} / \mathrm{gL}$ were biotinylated at a theoretical $1.5: 1$ biotin/protein ratio using the EZ-Link Sulfo-NHS-Biotin (ThermoFisher) at room temperature for 30min. Free biotin was removed by 3 successive rounds of dilution with PBS.

\section{Preparation of the antigen binding fragment}


1D8 Fab was obtained by digesting 1D8 lgG with Endoproteinase Lys-C (Sigma) at $37^{\circ} \mathrm{C}(1 \mathrm{mg}$ lgG: $250 \mathrm{ng}$ Lys $\mathrm{C})$ for $12 \mathrm{~h}$. Fab fragments were isolated with Fc fragments using protein A agarose, then further purified by SEC.

\section{Biolayer Interferometry (BLI)}

Antibody competition binding assays (Octet Red 96, ForteBio, Pall LLC): 250nM gH/gL was captured onto HIS1K sensors (ForteBio, Pall LLC) for 120s. The baseline interference was then read for $60 \mathrm{~s}$ in KB buffer (PBS, $0.1 \% \mathrm{BSA}$, $0.02 \%$ Tween). Then the sensor was loaded with 1D8 $(10 \mu \mathrm{g} / \mathrm{ml})$ or KB (blank) for 60 s and balanced in $\mathrm{KB}$ for $60 \mathrm{~s}$, followed by association with $10 \mu \mathrm{g} / \mathrm{ml}$ competitive antibodies (1D8, AMMO1, CL40, E1D1) for 120s and association with $\mathrm{KB}$ for $120 \mathrm{~s}$. One $\mathrm{gH} / \mathrm{gL}-1 \mathrm{D} 8$ loaded sensor was immersed in buffer as a reference during the association and dissociation steps and used to subtract the background signal.

Antibody/EphA2 competition binding assays: $2 \mu \mathrm{g} / \mathrm{ml} \mathrm{gH} / \mathrm{gL}$-biotin was immobilized on streptavidin biosensors (ForteBio, Pall LLC), and then immersed into KB for 60 s. Then the sensor was loaded with $1 \mathrm{D} 8(50 \mathrm{nM})$, AMMO1 (50nM), $2 \mathrm{G} 4$ (50nM) or KB (blank) for 60 s and balanced in KB for 60s, followed by associated with 1000nM EphA2-Fc for 100s and association with $\mathrm{KB}$ for $120 \mathrm{~s}$. One $\mathrm{gH} / \mathrm{gL}$-antibody loaded sensor was immersed in buffer as a reference during the association and dissociation steps and used to subtract the background signal. 


\section{Surface Plasmon Resonance (SPR)}

513 The binding kinetics and affinity of antibodies for $\mathrm{gH} / \mathrm{gL}$ or their mutants were 514 analyzed by SPR (Biacore 8K, GE Healthcare). Anti-human IgG (Fc) antibody 515 was covalently immobilized onto a CM5 sensor chip (GE Healthcare) via 516 amine groups in $10 \mathrm{mM}$ sodium acetate buffer $(\mathrm{pH} 5.0)$ for a final $\mathrm{RU}$ of around 517 5000. Specifically, antibodies $1 \mathrm{D} 8$ or AMMO1 $(2 \mu \mathrm{g} / \mathrm{ml})$ were captured by 518 anti-human $\operatorname{lgG}$ antibody for 10 s. Diluted $\mathrm{gH} / \mathrm{gL}$ or their mutants were run at a 519 flow rate of $30 \mu \mathrm{l} / \mathrm{min}$ in HBS-EP (aqueous buffer containing $0.01 \mathrm{M}$ HEPES $\mathrm{pH} 7.4,0.15 \mathrm{M} \mathrm{NaCl}, 3 \mathrm{mM}$ EDTA and $0.05 \%(\mathrm{v} / \mathrm{v})$ Tween 20, filtered through a $521 \quad 0.2 \mu \mathrm{m}$ filter). The sensograms were fit to a 1:1 binding model using the Biacore 522 Insight Evaluation Software (GE Healthcare).

\section{Enzyme-Linked Immunosorbent Assay (ELISA)}

525 For ELISA, 100ng/well of EBV glycoprotein was coated in 96-well enzyme-linked immunosorbent assay plates overnight at $4^{\circ} \mathrm{C}$. Then, the plates were blocked with $5 \%$ bovine serum albumin (BSA) in PBS and 0.1\%Tween-20

528 (blocking buffer) at $37^{\circ} \mathrm{C}$ for $1 \mathrm{~h}$. After blocking, the plates were washed three 529 times with $0.1 \%$ Tween-20 in PBS (washing buffer). Plasma samples or recombinant antibodies were diluted serially in blocking buffer and incubated

531 at $37^{\circ} \mathrm{C}$ for $1 \mathrm{~h}$. Following three times of washing, a 1:4000 goat anti-human IgG-HRP (Promega) in blocking buffer was added to each well and incubated 
533

at $37^{\circ} \mathrm{C}$ for 45 minutes. Plates were washed five times and incubated with 3,3',5,5'-tetramethylbenzidine substrate (TMB) (TIANGEN) for 5 minutes at room temperature. Then $1 \mathrm{M}$ hydrochloric acid $(\mathrm{HCl})$ was added and the $\mathrm{OD}_{450}$ was read on a microplate reader (Epoch2). For the binding analysis of $\mathrm{gH} / \mathrm{gL}$ mutants, $500 \mathrm{ng} /$ well of antibody was coated in plates overnight at $4^{\circ} \mathrm{C}$. The plates were then blocked and washed. The $\mathrm{gH} / \mathrm{gL}$ mutants were diluted serially in blocking buffer and incubated at $37^{\circ} \mathrm{C}$ for $1 \mathrm{~h}$. Following three times of washing, 1:3000 diluted mouse anti-his antibody (TRANSGEN BIOTECH) in blocking buffer was added to each well and incubated at $37^{\circ} \mathrm{C}$ for $1 \mathrm{~h}$. After three times of washing, a 1:5000 diluted goat anti-mouse-HRP antibody (Invitrogen) was added and incubated at $37^{\circ} \mathrm{C}$ for $1 \mathrm{~h}$. The final steps were the same as above.

\section{B cells sorting}

Cryopreserved 10 million PBMC were thawed into $1 \mathrm{ml}$ preheated RPMI1640, centrifuged at $300 \times \mathrm{g}$ for $5 \mathrm{~min}$, re-suspended in $500 \mu \mathrm{l}$ FACS buffer (PBS $+2 \%$ FBS), and incubated with $200 \mathrm{nM}$ his-tagged antigen ( $\mathrm{gH} / \mathrm{gL})$ for $45 \mathrm{~min}$ at $4^{\circ} \mathrm{C}$. The PBMC were then washed two times with $1 \mathrm{ml}$ FACS buffer and resuspended in $100 \mu \mathrm{l}$ FACS buffer. The PBMC were stained with the following antibodies: CD3-PE-Cy5 (BD Biosciences) at a 1:25 dilution, CD14-PE-Cy5 (eBioscience) at a 1:50 dilution, CD16-PE-Cy5 (BD Biosciences) at a 1:25 dilution, CD235a-PE-Cy5 (BD Biosciences) at a 1:100 dilution, 
555

556

557

558

559

560

561

562

563

564

565

566

567

568

569

570

571

572

573

574

575

576

CD19-APC-Cy7 (BD Biosciences) at a 1:100 dilution, CD20-PE-Cy7 (BD

Biosciences) at a 1:200 dilution, IgG-FITC (BD Biosciences) at a 1:25 dilution, and anti-his-PE (BioLegend) at a 1:20 dilution for $30 \mathrm{~min}$ at $4^{\circ} \mathrm{C}$. The PBMC were washed three times with $1 \mathrm{ml} \mathrm{FACS}$ buffer and resuspended in $500 \mu l$ FACS buffer, then subjected to FACS on a BD FACS Aria II (BD Biosciences). Antigen-positive B cells (CD3-, CD14-, CD16-, CD235a-, CD19+, CD20+, IgG+, $\mathrm{PE}+$ ) were sorted individually into 96-well PCR vital-plates containing $20 \mu \mathrm{l}$ first strand buffer $(5 \mu$ lirst strand buffer, $0.5 \mu \mathrm{l}$ of RNase inhibitor (Invitrogen), $1.25 \mu$ l of $100 \mu \mathrm{M}$ DTT, $0.06 \mu$ l of IGEPAL (Sigma).

\section{VH/VL recovery from sorted cells}

Wells containing sorted cells were mixed with $6 \mu$ l of reverse transcription (RT) buffer containing $1.5 \mu l$ mixed primers specific for human $\lg G, \lg M, \lg D, \lg A 1$, $\lg \mathrm{A} 2, \mathrm{~K}$ and $\lambda$ constant gene regions, $1.5 \mu \mathrm{l}$ of $25 \mathrm{mM}$ dNTP mix (Invitrogen), and $0.25 \mu \mathrm{l}$ of superscript III reverse transcriptase (Invitrogen). The RT temperature program included $42^{\circ} \mathrm{C}$ for $10 \mathrm{~min}, 25^{\circ} \mathrm{C}$ for $10 \mathrm{~min}, 60^{\circ} \mathrm{C}$ for 50 min, and $94^{\circ} \mathrm{C}$ for $5 \mathrm{~min}$, followed by a hold at $4^{\circ} \mathrm{C}$. The $\mathrm{VH}, \mathrm{VK}$ and $\mathrm{V} \lambda$ genes were amplified from $5 \mu \mathrm{l}$ of cDNA separately using nested PCR (HotStarTaq DNA Polymerase, QIAGEN). The PCR products were purified and subjected to Sanger sequencing. Then, the $\mathrm{VH}, \mathrm{VK}$ and $\mathrm{V} \lambda$ variable genes were assembled into functional linear $\lg$ gene expression cassettes by overlap-extension PCR. The function of the expressed antibodies was determined using ELISA 
screening.

\section{Virus production}

Akata cells carrying EBV, in which the thymidine kinase gene was interrupted with a double cassette expressing GFP and a neomycin resistance gene, were resuspended in FBS-free RPMI 1640 medium at a concentration of $2-3 \times 10^{6}$ cells per $\mathrm{ml}$, followed by induction with $0.75 \%(\mathrm{v} / \mathrm{v})$ of goat anti-human immunoglobulin G serum (Shuangliu Zhenglong Biochem Lab) for 6 h at $37^{\circ} \mathrm{C}$. After culture in fresh RPMI1640 medium supplemented with 5\% FBS for 3 days, virus from the supernatant was collected under sterile conditions, passed through two Millipore filters $(0.8$ and $0.45 \mu \mathrm{m})$, concentrated 100 -fold by high-speed centrifugation at 50,000g, and then resuspended in fresh FBS-free RPMI1640. The virus was stored at $80^{\circ} \mathrm{C}$ and thawed immediately before infection. To assess the virus titer, 10-fold dilutions of EBV were used to inoculate $2 \times 10^{5}$ PBMC per well in 24-well plates with $2 \mu \mathrm{g} / \mathrm{ml}$ cyclosporin A (CsA) (Sigma). The cultures were fed weekly by replacing half of the medium with fresh medium containing CsA. After 6 weeks, the $T_{50}$ was determined based on the number of proliferating lymphocytes in the wells (63).

\section{Neutralization assay}

Plasma samples from study individuals or recombinant antibodies were incubated with GFP-expressing EBV at serial dilutions for $3 \mathrm{~h}$ at $4^{\circ} \mathrm{C}$. Then the 
mixtures were added to Raji B cells or HNE1 epithelial cells and incubated for $3 \mathrm{~h}$ at $37^{\circ} \mathrm{C}$. Then the unbound virus was removed by washing with PBS twice. Infected cells were cultured in fresh medium for $48 \mathrm{~h}$, followed by detection and analysis of GFP-positive cells using a flow cytometer and FlowJo 10 software (FlowJo, USA). The neutralization rate of each sample was defined as: (\%GFP + cells in the positive control well containing virus alone - \%GFP+ cells in the plasma or antibody containing well)/\%GFP+ cells in the positive control well $\times 100$.

\section{EBV infection in humanized mice}

At 8 weeks post CD34+ stem cells transfer, $0.4 \mathrm{mg}$ of experimental or control antibodies were i.p. injected per humanized mouse. After $24 \mathrm{~h}$, the mice received a dose of Akata EBV equivalent to $1,000 \mathrm{TD}_{50}$ via i.v. injection. In the following period, the mice received a dose of $0.4 \mathrm{mg}$ antibody weekly. The blood collection and recording of body weight and health status were also done every week. The mice were euthanized 6 weeks post EBV infection or earlier if they became clinically ill (e.g. body weight loss of approximately $20 \%)$.

\section{Detection of EBV DNA in blood and tissues}

DNA was extracted from the peripheral blood $(100 \mu l)$ or tissues of the mice using commercial DNA extraction kits (Omega). The EBV genome copy 
621 622 TaqMan BamHI probes (40) as described previously. The copy numbers of

number was determined by real-time PCR (Roche Light Cycler 480) using the EBV were quantified using a standard EBV genome (BDS biotech) as control.

\section{H\&E staining, IHC, and in situ hybridization}

Tissues were fixed in $10 \%$ formalin and embedded in paraffin. Consecutive sections were used for staining with H\&E. Immunostaining of human T cells and $\mathrm{B}$ cells was performed using hCD3 antibody (VENTANA) and hCD20 antibody (VENTANA) at 1:200 dilution. EBERs were stained by in situ hybridization using the EBER detection kit (ZSGB-BIO), according to the manufacturer's instructions. Histological staining was evaluated by experienced pathologists.

\section{Detection of human immune cells in the blood of humanized mice}

Peripheral blood of mice was treated with $1 \mathrm{ml}$ red blood cell lysis buffer (BioLegend) at room temperature for $10 \mathrm{~min}$. Then the cells were centrifuged at $300 \times \mathrm{g}$, washed twice with PBS, re-suspended in PBS, and stained with antibodies including anti-human CD45-PE (BD Biosciences), CD3-PerCP-Cy5.5 (BD Biosciences) and CD20-FITC (BD Biosciences) at 1:100 dilution for $30 \mathrm{~min}$ at $4^{\circ} \mathrm{C}$. After washing with PBS, the percentage of CD3+ or CD20+ cells among the CD45+ cells was quantified using a flow cytometer. 


\section{Cell surface binding assays}

645 For the cell-surface binding assay, $1 \mathrm{mg}$ of $\mathrm{gH} / \mathrm{gL}$-biotin conjugated with SA-PE ( $\mathrm{gH} / \mathrm{gL}-\mathrm{PE})$ was diluted in $10 \mathrm{ml}$ of PBS into individual wells of a 96 well plate.

647

An equimolar amount of gp42 was added to select wells containing gH/gL-PE. $5 \mathrm{mg} / \mathrm{ml}$ of monoclonal antibodies, including 1D8, AMMO1, or 2G4, were added to select wells containing $\mathrm{gH} / \mathrm{gL}$ with or without gp42 and incubated for $1 \mathrm{~h}$ at $37^{\circ} \mathrm{C}$. At the same time, adherent $\mathrm{HK} 1$ cells were trypsinized (NCM Biotech), washed with RMPI 1640 and then allowed to recover at $37^{\circ} \mathrm{C}$ in a humidified atmosphere comprising $5 \% \mathrm{CO}_{2}$ for $1 \mathrm{~h}$ with gentle agitation twice during the period. Recovered HK1 and Raji cells were pelleted by centrifugation at $300 \times$ $\mathrm{g}$ for $5 \mathrm{~min}$ and then resuspended at a density of $2 \times 10^{6} \mathrm{cell} / \mathrm{s} / \mathrm{ml}$ in ice-cold $0.5 \%$ bovine serum albumin (BSA) in PBS. Then, $100 \mu \mathrm{l}$ of the HK1 or Raji cells suspension were added to wells containing SA-PE, gH/gL-PE with or without gp42 and antibodies, and incubated on ice for $1 \mathrm{~h}$. The cells were pelleted by centrifugation at $300 \times \mathrm{g}$ for $5 \mathrm{~min}$, washed with $1 \mathrm{ml}$ of ice cold $0.5 \%$ BSA in PBS, pelleted again and resuspended in $10 \%$ phosphate buffered formalin. The amount of PE staining was quantified using a flow cytometer.

\section{Virus-free fusion assay}

Effector $\mathrm{CHO}-\mathrm{K} 1$ cells were transiently transfected with expression plasmid (pCAGGS-gH, pCAGGS-gL, pCAGGS-gB and pT7EMCLuc, which carries a 
665

666

667

668

669

670

671

672

673

674

675

676

677

678

679

680

681

682

683

684

685

686

luciferase-containing reporter plasmid under the control of the T7 promoter). Target cells (HEK-293T) were transfected with expression plasmid pCAGT7 (expressing T7 DNA polymerase). After $24 \mathrm{~h}$, the effector cells were trypsinized and re-suspended at a density of $1 \times 10^{6} \mathrm{cells} / \mathrm{ml}$. Aliquots comprising $250 \mu / /$ well of effector cell suspension was pre-incubated with $2 \mu \mathrm{g} 1 \mathrm{D} 8$, AMMO1 or $2 \mathrm{G} 4$ antibody at $37^{\circ} \mathrm{C}$ for $1 \mathrm{~h}$. Then the target cells were also trypsinized and re-suspended at a density of $1 \times 10^{6} \mathrm{cell} / \mathrm{s} / \mathrm{ml}$. An aliquot comprising $250 \mu \mathrm{l}$ of the effector cell suspension was added to the effector cells with or without antibody. After $24 \mathrm{~h}$, the medium was aspirated and the cells were lysed in $100 \mu$ l of luciferase agent (Dual-Glo Luciferase Assay System). Then, $75 \mu$ l of cell lysate was transferred to a white-bottom assay plate and luciferase activity was read on a GloMax-96 Microplate Luminometer (Promega).

\section{Cell surface staining}

Following $24 \mathrm{~h}$ after expression plasmid transfection, the effector $\mathrm{CHO}-\mathrm{K} 1$ cells were trypsinized and re-suspended at a density of $1 \times 10^{6} \mathrm{cells} / \mathrm{ml}$. The expression level of $\mathrm{gH} / \mathrm{gL}$ was detected using the indicated antibody. AMMO1 and $1 \mathrm{D} 8$ were used for $\mathrm{gH} / \mathrm{gL}$ staining and $2 \mathrm{G} 4$ as a control. Then, $10 \mu \mathrm{g} / \mathrm{ml}$ of antibody was added to the cell suspension and incubated at $4^{\circ} \mathrm{C}$ for $1 \mathrm{~h}$. The cells were washed twice with PBS and stained with human IgG-PerCP-Cy5.5 (PC5.5) (BioLegend) at a 1:100 dilution. After washing with PBS, the 
687

688

689

690

691

692

693

694

695

696

697

698

699

700

701

702

703

704

705

706

707

708

percentage of PC5.5+ cells was quantified using a flow cytometer (CytoFLEX, BECKMAN).

\section{Crystallization of the 1D8 Fab and data collection}

To purify the $\mathrm{gH} / \mathrm{gL}-1 \mathrm{D} 8$ Fab complex, 1D8 Fab was incubated with $\mathrm{gH} / \mathrm{gL}$ for 1 $h$ on ice in HBS buffer, and the mixture was then subjected to gel filtration chromatography. Fractions containing the complex were pooled and concentrated to $10 \mathrm{mg} / \mathrm{ml}$. Crystals were successfully grown at $18^{\circ} \mathrm{C}$ in sitting drops, over wells containing $200 \mathrm{mM}$ sodium citrate, $100 \mathrm{mM}$ HEPES sodium salt, $\mathrm{pH} 7.5,15 \% \mathrm{w} / \mathrm{v}$ MPD. The drops were made by mixing $200 \mathrm{nl}$ gH/gL-1D8 Fab complex in HBS buffer with 200 nl well solution. Crystals were harvested, soaked briefly in $200 \mathrm{mM}$ sodium citrate, $100 \mathrm{mM}$ HEPES sodium salt, $\mathrm{pH} 7.5,15 \% \mathrm{w} / \mathrm{v}$ MPD, 20\% glycerol, and flash-frozen in liquid nitrogen. Diffraction data were collected at the BL17U beam line of the Shanghai Synchrotron Research Facility (SSRF). Diffraction data were processed with HKL2000 and the crystal diffracted to $4.2 \AA$. The data processing statistics are listed in Supplementary Table 3.

\section{Structure solution and refinement}

The structure was determined via the molecular replacement method using PHASER in CCP4 suite. The search models were $\mathrm{gH} / \mathrm{gL}$ (PDB code 5T1D) and the antibody with the highest sequence identity with 1D8. Density map 
improvement by atoms update and refinement was performed with ARP/wARP29. Subsequent model building and refinement were performed using COOT and PHENIX, respectively. Final Ramachandran statistics indicated that $91.48 \%$ residues were in favored conformations, $7.06 \%$ allowed and $1.46 \%$ outliers for the final structure. The structural refinement statistics are listed in Supplementary Table 3. All structural figures were generated with PyMol (DeLano, 2002).

\section{Statistical analysis}

Unless noted otherwise, a two-tailed, unpaired $t$-test was used to assess statistical significance. Statistical calculations were performed in GraphPad Prism 8. The number of replicates and a description of the statistical method are provided in the corresponding figure legends. Differences with $\mathrm{P}$ values of less than 0.05 were considered to be statistically significant. ${ }^{*} P<0.05,{ }^{* *} P<$ $0.01,{ }^{* * *} P<0.001$, ns $=$ not significant.

\section{REFERENCES AND NOTES}

1. G. de-The et al., Sero-epidemiology of the Epstein-Barr virus: preliminary analysis of an international study - a review. IARC Sci Publ, 3-16 (1975).

2. L. S. Young, L. F. Yap, P. G. Murray, Epstein-Barr virus: more than 50 years old and still providing surprises. Nat Rev Cancer 16, 789-802 (2016).

3. J. I. Cohen, A. S. Fauci, H. Varmus, G. J. Nabel, Epstein-Barr virus: an important vaccine target for cancer prevention. Sci Transl Med 3, 107 fs107 (2011).

4. L. S. Young, C. W. Dawson, Epstein-Barr virus and nasopharyngeal carcinoma. Chin J Cancer 33, 581-590 (2014).

5. S. E. Henrickson, To EBV or not to EBV: Rational vaccine design for a common infection. Sci Immunol 3, (2018).

6. D. G. van Zyl, J. Mautner, H. J. Delecluse, Progress in EBV Vaccines. Front Oncol 9, 104 (2019). 
7. J. I. Cohen, Epstein-barr virus vaccines. Clin Transl Immunology 4, e32 (2015).

8. J. I. Cohen, E. S. Mocarski, N. Raab-Traub, L. Corey, G. J. Nabel, The need and challenges for development of an Epstein-Barr virus vaccine. Vaccine 31 Suppl 2, B194-196 (2013).

9. W. Bu et al., Immunization with Components of the Viral Fusion Apparatus Elicits Antibodies That Neutralize Epstein-Barr Virus in B Cells and Epithelial Cells. Immunity 50, 1305-1316 e1306 (2019).

10. A. E. Coghill et al., High Levels of Antibody that Neutralize B-cell Infection of Epstein-Barr Virus and that Bind EBV gp350 Are Associated with a Lower Risk of Nasopharyngeal Carcinoma. Clin Cancer Res 22, 3451-3457 (2016).

11. A. E. Coghill et al., Evaluation of Total and IgA-Specific Antibody Targeting Epstein-Barr Virus Glycoprotein 350 and Nasopharyngeal Carcinoma Risk. J Infect Dis 218, 886-891 (2018).

12. W. Bu et al., Kinetics of Epstein-Barr Virus (EBV) Neutralizing and Virus-Specific Antibodies after Primary Infection with EBV. Clin Vaccine Immunol 23, 363-369 (2016).

13. J. Sashihara, P. D. Burbelo, B. Savoldo, T. C. Pierson, J. I. Cohen, Human antibody titers to Epstein-Barr Virus (EBV) gp350 correlate with neutralization of infectivity better than antibody titers to EBV gp42 using a rapid flow cytometry-based EBV neutralization assay. Virology 391, 249-256 (2009).

14. D. Sok, D. R. Burton, Recent progress in broadly neutralizing antibodies to HIV. Nat Immunol 19, 1179-1188 (2018).

15. E. O. Saphire, S. L. Schendel, B. M. Gunn, J. C. Milligan, G. Alter, Antibody-mediated protection against Ebola virus. Nat Immunol 19, 1169-1178 (2018).

16. F. Yu et al., Receptor-binding domain-specific human neutralizing monoclonal antibodies against SARS-CoV and SARS-CoV-2. Signal Transduct Target Ther 5, 212 (2020).

17. L. M. Walker, D. R. Burton, Passive immunotherapy of viral infections: 'super-antibodies' enter the fray. Nat Rev Immunol 18, 297-308 (2018).

18. A. Lanzavecchia, A. Fruhwirth, L. Perez, D. Corti, Antibody-guided vaccine design: identification of protective epitopes. Curr Opin Immunol 41, 62-67 (2016).

19. L. M. Hutt-Fletcher, EBV glycoproteins: where are we now? Future Virol 10, 1155-1162 (2015).

20. B. S. Mohl, J. Chen, R. Longnecker, Gammaherpesvirus entry and fusion: A tale how two human pathogenic viruses enter their host cells. Adv Virus Res 104, 313-343 (2019).

21. T. Haque et al., A mouse monoclonal antibody against Epstein-Barr virus envelope glycoprotein 350 prevents infection both in vitro and in vivo. J Infect Dis 194, 584-587 (2006).

22. J. Snijder et al., An Antibody Targeting the Fusion Machinery Neutralizes Dual-Tropic Infection and Defines a Site of Vulnerability on Epstein-Barr Virus. Immunity 48, 799-811 e799 (2018).

23. X. Cui et al., Rabbits immunized with Epstein-Barr virus $\mathrm{gH} / \mathrm{gL}$ or $\mathrm{gB}$ recombinant proteins elicit higher serum virus neutralizing activity than gp350. Vaccine 34, 4050-4055 (2016).

24. S. A. Connolly, J. O. Jackson, T. S. Jardetzky, R. Longnecker, Fusing structure and function: a structural view of the herpesvirus entry machinery. Nat Rev Microbiol 9, 369-381 (2011).

25. S. Singh et al., Neutralizing Antibodies Protect against Oral Transmission of Lymphocryptovirus. Cell Rep Med 1, (2020).

26. B. S. Mohl, J. Chen, K. Sathiyamoorthy, T. S. Jardetzky, R. Longnecker, Structural and Mechanistic Insights into the Tropism of Epstein-Barr Virus. Mol Cells 39, 286-291 (2016).

27. S. A. Connolly, T. S. Jardetzky, R. Longnecker, The structural basis of herpesvirus entry. Nat Rev Microbiol, (2020). 
28. L. S. Chesnokova, L. M. Hutt-Fletcher, Epstein-Barr virus infection mechanisms. Chin J Cancer 33, 545-548 (2014).

29. H. Matsuura, A. N. Kirschner, R. Longnecker, T. S. Jardetzky, Crystal structure of the Epstein-Barr virus (EBV) glycoprotein H/glycoprotein L (gH/gL) complex. Proc Natl Acad Sci U S A 107, 22641-22646 (2010).

30. B. S. Mohl, K. Sathiyamoorthy, T. S. Jardetzky, R. Longnecker, The conserved disulfide bond within domain II of Epstein-Barr virus gH has divergent roles in membrane fusion with epithelial cells and B cells. J Virol 88, 13570-13579 (2014).

31. J. Chen, T. S. Jardetzky, R. Longnecker, The large groove found in the $\mathrm{gH} / \mathrm{gL}$ structure is an important functional domain for Epstein-Barr virus fusion. J Virol 87, 3620-3627 (2013).

32. K. Sathiyamoorthy et al., Assembly and architecture of the EBV B cell entry triggering complex. PLoS Pathog 10, e1004309 (2014).

33. M. Kanekiyo et al., Rational Design of an Epstein-Barr Virus Vaccine Targeting the Receptor-Binding Site. Cell 162, 1090-1100 (2015).

34. K. A. Young, A. P. Herbert, P. N. Barlow, V. M. Holers, J. P. Hannan, Molecular basis of the interaction between complement receptor type 2 (CR2/CD21) and Epstein-Barr virus glycoprotein gp350. J Virol 82, 11217-11227 (2008).

35. G. Szakonyi et al., Structure of the Epstein-Barr virus major envelope glycoprotein. Nat Struct Mol Biol 13, 996-1001 (2006).

36. K. Sathiyamoorthy et al., Structural basis for Epstein-Barr virus host cell tropism mediated by gp42 and gHgL entry glycoproteins. Nat Commun 7, 13557 (2016).

37. M. M. Mullen, K. M. Haan, R. Longnecker, T. S. Jardetzky, Structure of the Epstein-Barr virus gp42 protein bound to the MHC class II receptor HLA-DR1. Mol Cell 9, 375-385 (2002).

38. A. N. Kirschner, J. Omerovic, B. Popov, R. Longnecker, T. S. Jardetzky, Soluble Epstein-Barr virus glycoproteins $\mathrm{gH}, \mathrm{gL}$, and gp42 form a 1:1:1 stable complex that acts like soluble gp42 in B-cell fusion but not in epithelial cell fusion. J Virol 80, 9444-9454 (2006).

39. J. Chen et al., Ephrin receptor A2 is a functional entry receptor for Epstein-Barr virus. Nat Microbiol 3, 172-180 (2018).

40. H. Zhang et al., Ephrin receptor A2 is an epithelial cell receptor for Epstein-Barr virus entry. Nat Microbiol 3, 1-8 (2018).

41. H. B. Wang et al., Neuropilin 1 is an entry factor that promotes EBV infection of nasopharyngeal epithelial cells. Nat Commun 6, 6240 (2015).

42. J. Chen, R. Longnecker, Epithelial cell infection by Epstein-Barr virus. FEMS Microbiol Rev 43, 674-683 (2019).

43. K. Sathiyamoorthy et al., Inhibition of EBV-mediated membrane fusion by anti-gHgL antibodies. Proc Natl Acad Sci U S A 114, E8703-E8710 (2017).

44. Z. Liu et al., Two Epstein-Barr virus-related serologic antibody tests in nasopharyngeal carcinoma screening: results from the initial phase of a cluster randomized controlled trial in Southern China. Am J Epidemiol 177, 242-250 (2013).

45. Y. Liu et al., Establishment of VCA and EBNA1 IgA-based combination by enzyme-linked immunosorbent assay as preferred screening method for nasopharyngeal carcinoma: a two-stage design with a preliminary performance study and a mass screening in southern China. Int J Cancer 131, 406-416 (2012).

46. S. Fujiwara, K. Imadome, M. Takei, Modeling EBV infection and pathogenesis in 
new-generation humanized mice. Exp Mol Med 47, e135 (2015).

47. E. K. Lee et al., Effects of lymphocyte profile on development of EBV-induced lymphoma subtypes in humanized mice. Proc Natl Acad Sci U S A 112, 13081-13086 (2015).

48. C. Munz, Humanized mouse models for Epstein Barr virus infection. Curr Opin Virol 25, 113-118 (2017).

49. E. A. Caves et al., Air-Liquid Interface Method To Study Epstein-Barr Virus Pathogenesis in Nasopharyngeal Epithelial Cells. mSphere 3, (2018).

50. R. Lin et al., Development of a robust, higher throughput green fluorescent protein (GFP)-based Epstein-Barr Virus (EBV) micro-neutralization assay. J Virol Methods 247, 15-21 (2017).

51. D. R. Burton, L. Hangartner, Broadly Neutralizing Antibodies to HIV and Their Role in Vaccine Design. Annu Rev Immunol 34, 635-659 (2016).

52. L. L. Lu, T. J. Suscovich, S. M. Fortune, G. Alter, Beyond binding: antibody effector functions in infectious diseases. Nat Rev Immunol 18, 46-61 (2018).

53. G. Zhou, Q. Zhao, Perspectives on therapeutic neutralizing antibodies against the Novel Coronavirus SARS-CoV-2. Int J Biol Sci 16, 1718-1723 (2020).

54. O. A. Odumade, K. A. Hogquist, H. H. Balfour, Jr., Progress and problems in understanding and managing primary Epstein-Barr virus infections. Clin Microbiol Rev 24, 193-209 (2011).

55. B. S. Mohl, J. Chen, S. J. Park, T. S. Jardetzky, R. Longnecker, Epstein-Barr Virus Fusion with Epithelial Cells Triggered by gB Is Restricted by a gL Glycosylation Site. J Virol 91, (2017).

56. J. Omerovic, L. Lev, R. Longnecker, The amino terminus of Epstein-Barr virus glycoprotein gH is important for fusion with epithelial and B cells. J Virol 79, 12408-12415 (2005).

57. F. Zhan et al., [Primary study of differentially expressed cDNA sequences in cell line HNE1 of human nasopharyngeal carcinoma by cDNA representational difference analysis]. Zhonghua Yi Xue Yi Chuan Xue Za Zhi 15, 341-344 (1998).

58. D. P. Huang et al., Establishment of a cell line (NPC/HK1) from a differentiated squamous carcinoma of the nasopharynx. Int J Cancer 26, 127-132 (1980).

59. S. J. Molesworth, C. M. Lake, C. M. Borza, S. M. Turk, L. M. Hutt-Fletcher, Epstein-Barr virus gH is essential for penetration of $B$ cells but also plays a role in attachment of virus to epithelial cells. J Virol 74, 6324-6332 (2000).

60. S. Guo et al., Oncological and genetic factors impacting PDX model construction with NSG mice in pancreatic cancer. FASEB J 33, 873-884 (2019).

61. J. Chen, S. Schaller, T. S. Jardetzky, R. Longnecker, EBV gH/gL and KSHV gH/gL bind to different sites on EphA2 to trigger fusion. J Virol, (2020).

62. H. X. Liao et al., High-throughput isolation of immunoglobulin genes from single human $B$ cells and expression as monoclonal antibodies. J Virol Methods 158, 171-179 (2009).

63. M. Yajima et al., A new humanized mouse model of Epstein-Barr virus infection that reproduces persistent infection, lymphoproliferative disorder, and cell-mediated and humoral immune responses. J Infect Dis 198, 673-682 (2008).

Acknowledgements: We thank Chang Song and Cui Qiao from Beijing IDMO

Company for help with the animal experiment. The plasmids pCAGGS-T7, 
867

868

869

870

871

872 873 Guangdong Province key research and development program 874

875

876

877

878

879

880

881

882

883

884

885

886

887

888

pCAGGS-gH, pCAGGS-gL, pCAGGS-gB and pT7EMCLuc were kindly provided by Professor Richard Longnecker. Funding: This work was supported by the following grant supports: the National Key Research and Development Program of China (2017YFA0505600, 2016YFA0502100, 2018ZX10731101-002, 2017ZX10201101), the National Natural Science Foundation of China $(81530065,81520108022,81830090$ and 81621004), (2019B020226002) and Beijing Municipal Science \& Technology Commission (Z181100001918043, 171100000517). Author contributions: L.Z., M.Z., and X.W. conceptualized the study. Q.Z., S.S., J.Y., Y.Z., and C.S. performed experiments and analyzed data. Q.Z., S.S., J.Y., L.Z., M.Z., and X.W. wrote the manuscript, and all authors contributed to editing and figure preparation. Funding was secured by L.Z., M.Z., and X.W. Competing interests: The authors declare no potential conflicts of interest. Data availability: The atomic model of 1D8-gH/gL (PDB ID: 7D5Z) has been deposited in the Protein Data Bank. 


\section{MAIN FIGURE LEGENDS}

Fig. 1. Isolation of $\mathrm{gH} / \mathrm{gL}$-specific monoclonal antibodies using single $\mathrm{B}$ cell sorting and cloning. (A) FACS-based sorting strategy for $\mathrm{gH} / \mathrm{gL}$-specific B cells. (B) Binding activities of 1D8 and 2A6, the positive control AMMO1, and the negative control $2 \mathrm{G} 4$ to $\mathrm{EBV} \mathrm{gH} / \mathrm{gL}$ measured by ELISA. The data are presented as means \pm SEM. (C) Neutralizing activities of $1 \mathrm{D} 8$ and 2A6, the positive control AMMO1, and the negative control 2G4 against EBV infection of Raji B cell lines and (D) HNE1 epithelia cell line. The data shown is means \pm SEM. SSC-A, side-scatter area; FSC-A, forward-scatter area.

\section{Fig. 2. Protective efficacy of 1D8 against lethal EBV challenge in} humanized mice. (A) Timeline for engrafting CD34+ human hematopoietic stem cells (HSC), antibody administration, viral challenge, and monitoring for various biological and clinical outcomes. Four hundred micrograms of 1D8, positive control AMMO1, negative control 2G4, or PBS negative control were administered to the humanized mice via intraperitoneal injection either $24 \mathrm{~h}$ prior to or weekly for 5 weeks after intravenous challenge with Akata EBV. (B) EBV DNA in the peripheral blood, (C) body weight, and (D) survival were monitored weekly. The percent changes in $(\mathbf{E})$ hCD45+, $(\mathbf{F})$ hCD20+, or $(\mathbf{G})$ hCD3+ cells over the experiment period. On week 6 post infection, $(\mathbf{H})$ virus titers in spleen, (I) liver, ( $\mathbf{J})$ kidney were analyzed. All data are presented as mean \pm SEM. ${ }^{*} p<0.05 ;{ }^{* *} p<0.01 ;{ }^{* * *} p<0.001 ; n s$, no significant. 
Fig. 3. 1D8 reduces viral replication and tissue damages in humanized

mice. Representative of macroscopic spleens and splenic sections stained for hematoxylin and eosin (H\&E), EBV encoded RNA (EBER), human CD20 (hCD20), and human CD3 (hCD3) at necropsy. The scale bars are indicated.

Fig. 4. 1D8 targets an unique epitope on $\mathbf{g H} / \mathbf{g L}$. (A) Structure overview in a cartoon representation with $\mathrm{gL}$ in cyan, $\mathrm{gH}$ D-I in blue, D-II in wheat, D-III in green, D-IV in yellow, and 1D8 Fab in purple. The map is contoured at 1.2 RMS to show the density. (B) Zoomed-in view of the interaction between 1D8 and D-I and D-II. The key binding residue N310 of $\mathrm{gH}$ was indicated by a red star. (C) Cartoon representation of Fab 1D8 and other previously published Fabs AMMO1, CL40, and E1D1 bound to a single $\mathrm{gH} / \mathrm{gL}$ molecule. The color scheme for $\mathrm{gH} / \mathrm{gL}$ is as in (A) whereas 1D8 Fab in purple, AMMO1 Fab in light the four Fab epitopes on $\mathrm{gH} / \mathrm{gL}$ with the same color in (C). Areas in black indicate the region where structural change was found upon binding to AMMO1 or CL40.

Fig. 5. 1D8 interferes with cell fusion and binding. Quality control of $\mathrm{gH} / \mathrm{gL}$ expression on the surface of $\mathrm{CHO}-\mathrm{K} 1$ cells by staining with 1D8 $(\mathbf{A})$, positive 
933

934

935

936

937

938

939

940

941

942

943

944

945

946

947

948

949

950

951

952

953

954

fusion experiment shown in (D). (D) Marked reduction in cell-cell fusion in the presence of 1D8, the positive control AMMMO1, but not the negative control 2G4. Marked reduction in $\mathrm{gH} / \mathrm{gL}$ binding to Raji $\mathrm{B}$ cell (E) and HK1 epithelial cell $(\mathbf{F})$ in the presence of 1D8, the positive control AMMO1, but not the negative control 2G4. Binding of EphA1-Fc to $\mathrm{gH} / \mathrm{gL}$ was reduced by 1D8 (G), but not by AMMO1 (H) or 2G4 (I) measured by Bio-layer interferometry (BLI). All data are presented as mean \pm SEM. ${ }^{*} p<0.05 ;{ }^{* *} p<0.01 ;{ }^{* \star *} p<0.001$; ns, no significant. SSC-A, side-scatter area; PC5.5, PerCP-Cy5.5; RLU, relative light unit; SA-PE, streptavidin-phycoerythrin; MFI, mean fluorescence intensity.

\section{Fig. 6. Possible mechanisms of 1D8-mediated neutralization. (A) For} epithelia cells, 1D8 could interfere the interaction between $\mathrm{gH} / \mathrm{gL}$ and EphA2 either by directly restricting access to the interface or by indirectly posing allosteric hindrance. It could also restrict the movement across the D-I/D-II groove of $\mathrm{gH} / \mathrm{gL}$ that is required for $\mathrm{gB}$ interaction and triggering. (B) For $\mathrm{B}$ cells, 1D8 could also restrict the movement across the D-I/D-II groove of $\mathrm{gH} / \mathrm{gL}$ that is required for downstream viral entry. 1D8 does not appear influence interaction between gp42 and its receptor HLA class II. 
Fig. 1
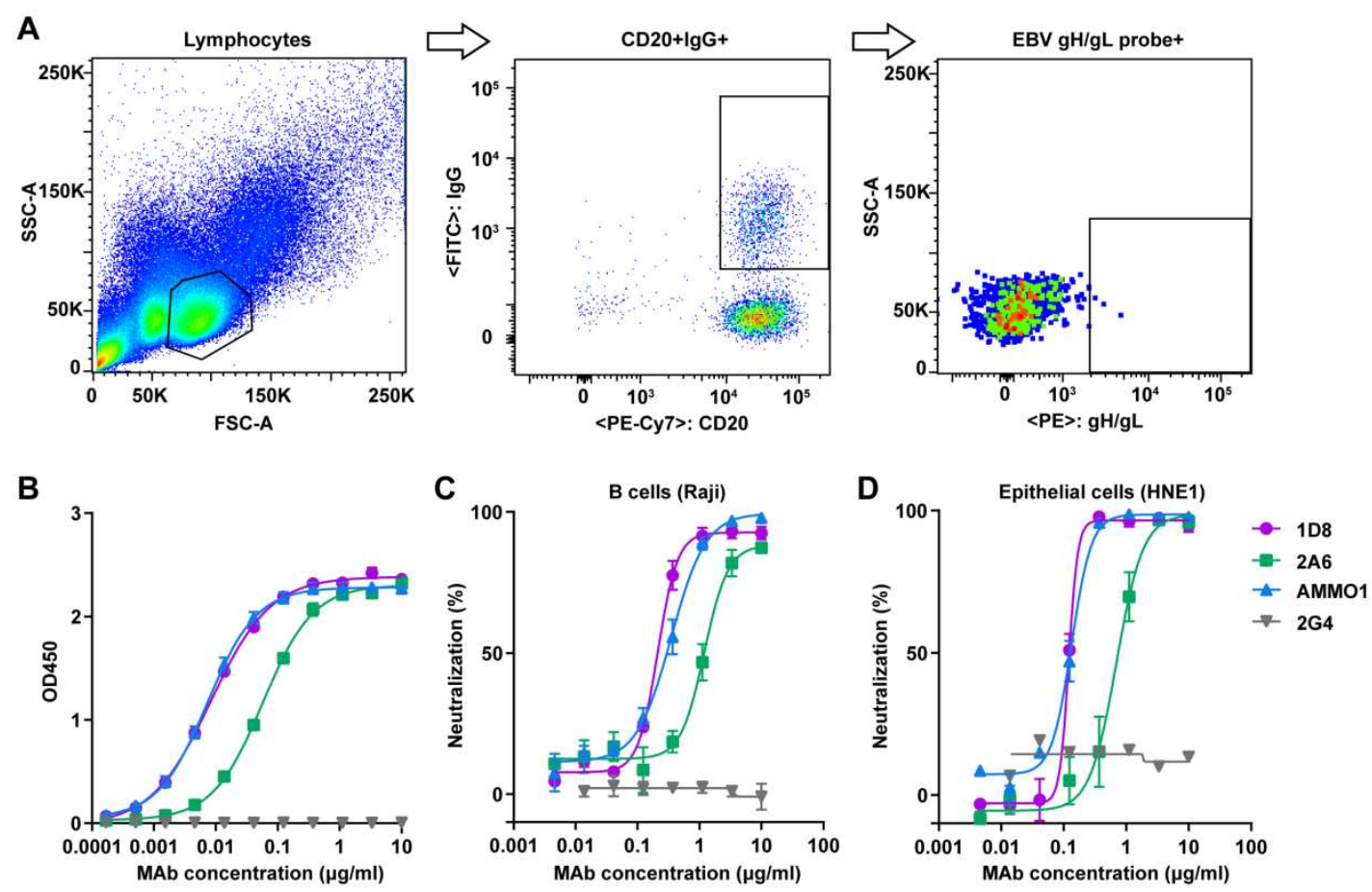

956

957

958

959

960

961

962

963

964

965

966

967 


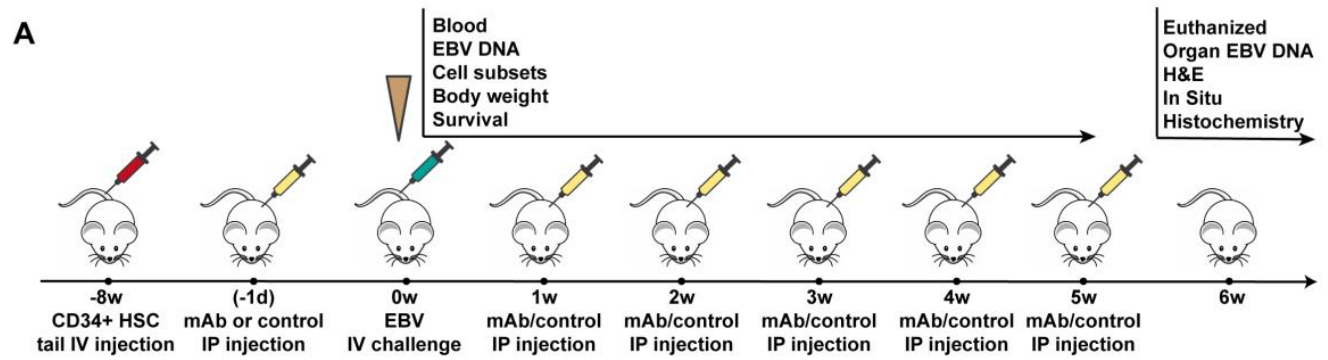

B

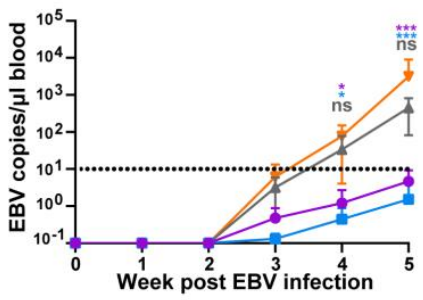

E
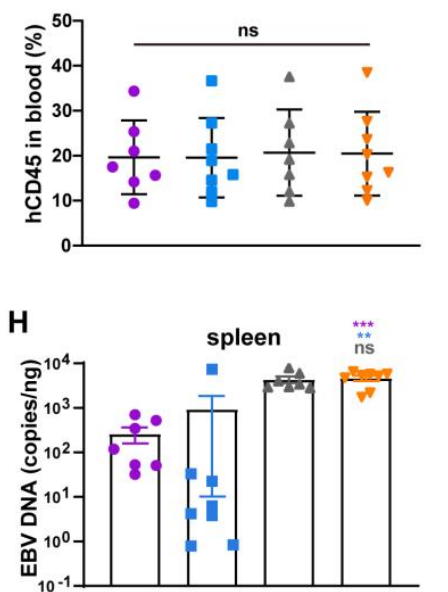

C

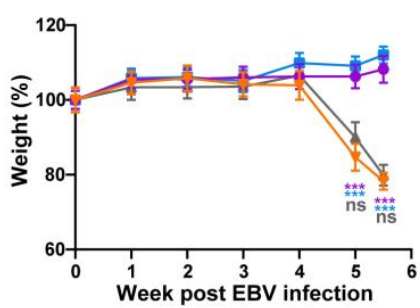

F

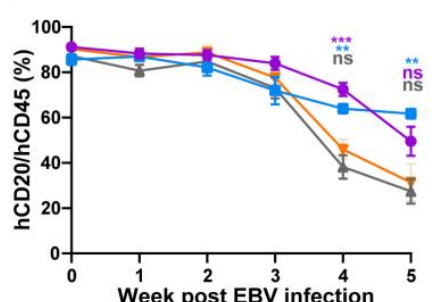

I

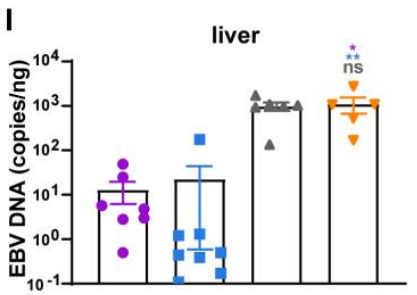

D

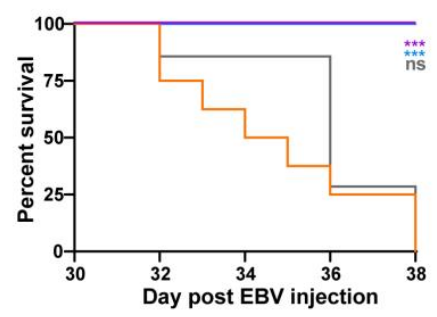

G

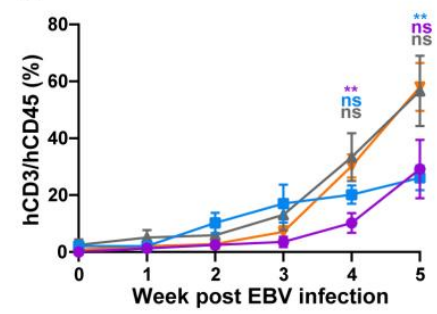

J

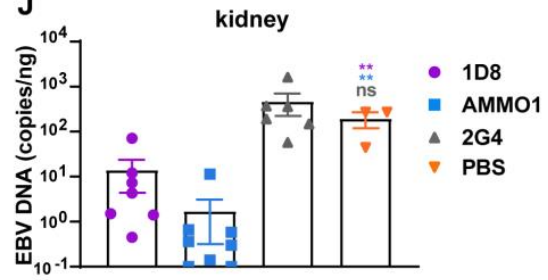


Fig. 3

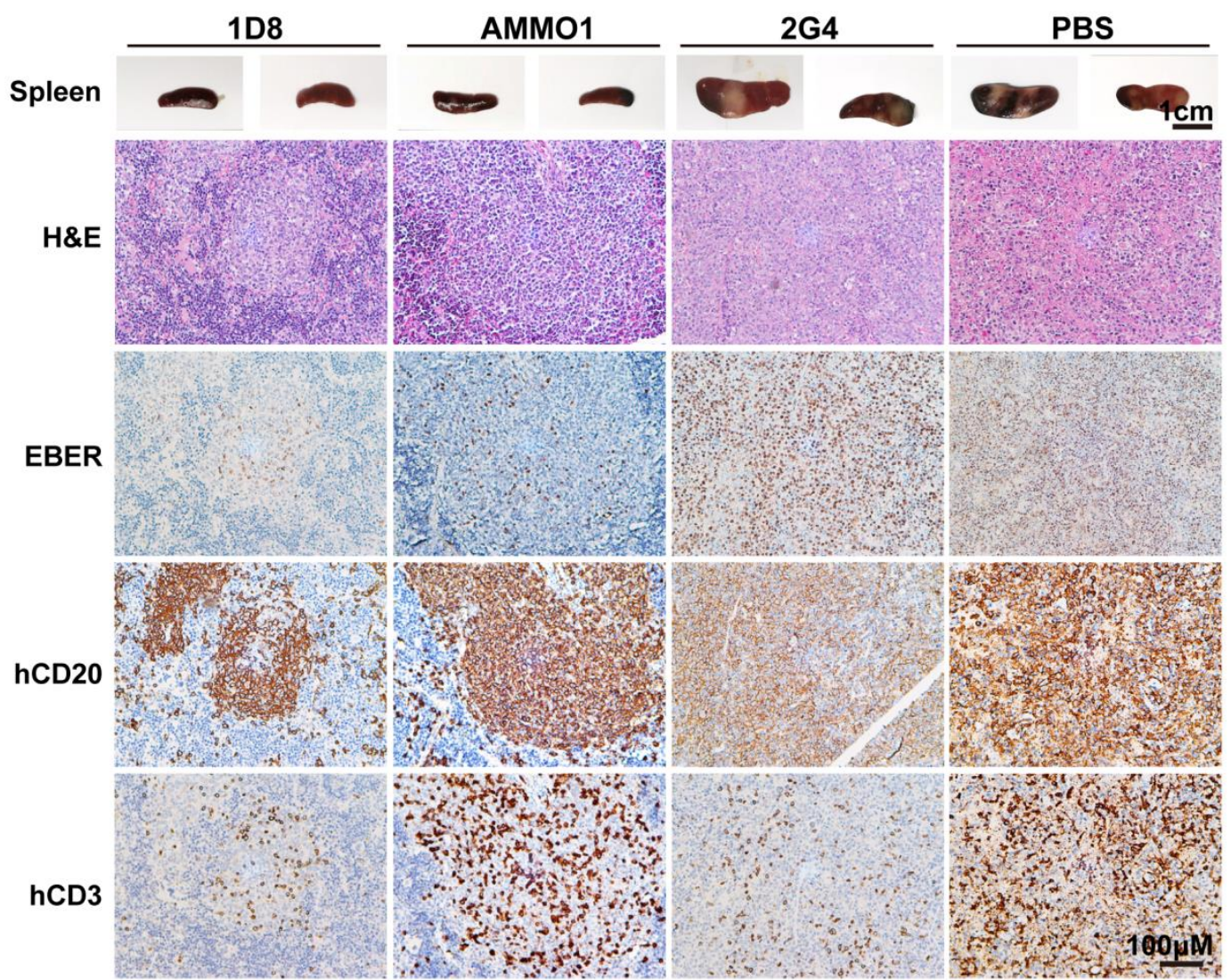

980

981

982

983

984

985

986

987

988

989

990 
Fig. 4
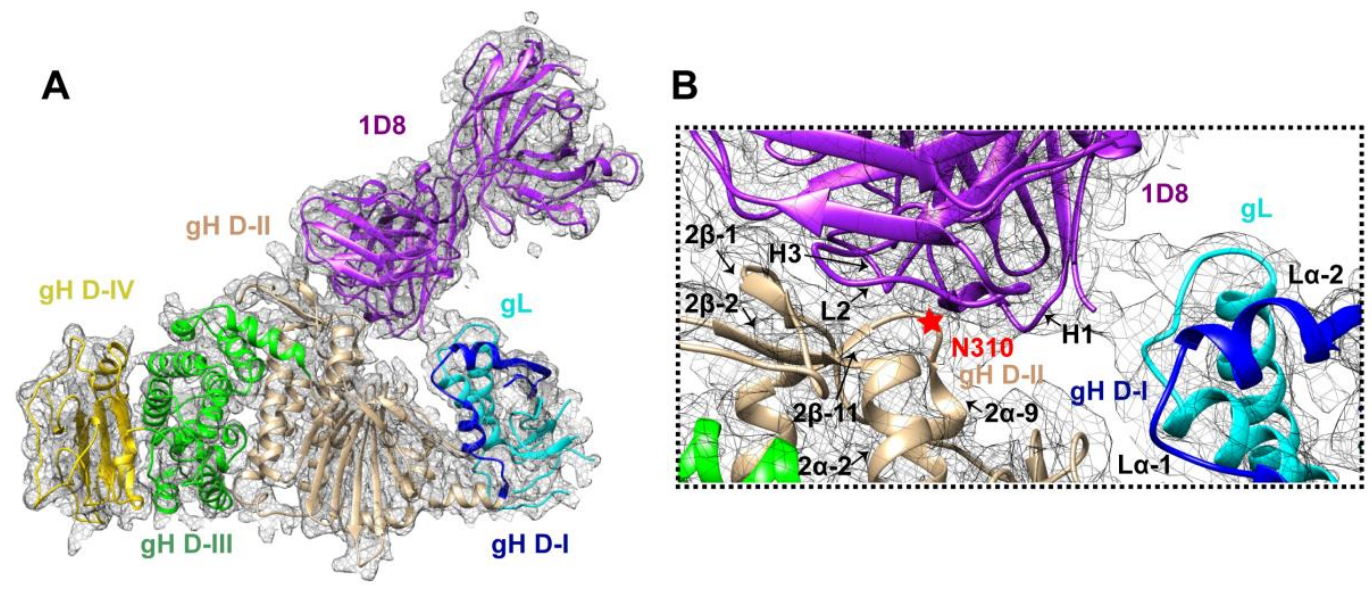

C

D
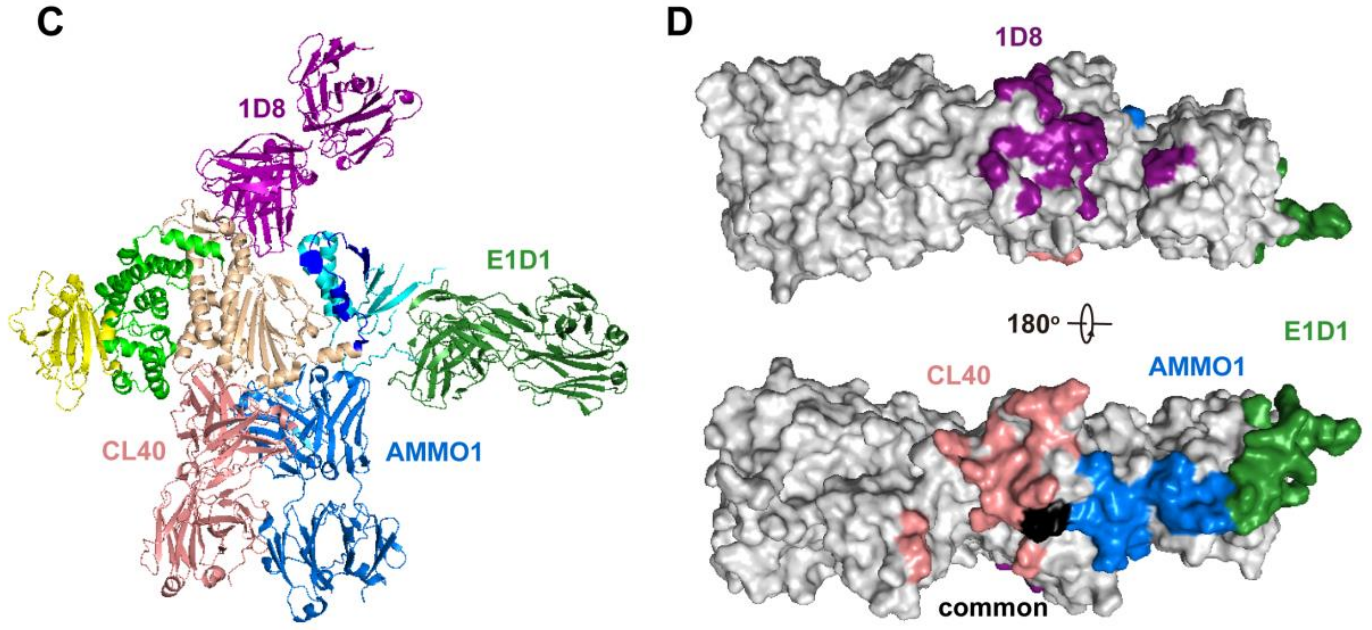

992

993

994

995

996

997

998

999

1000

1001 
Fig. 5

A

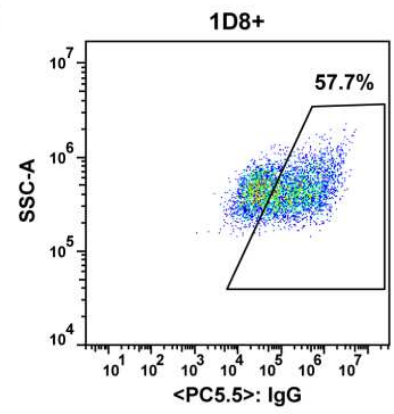

D

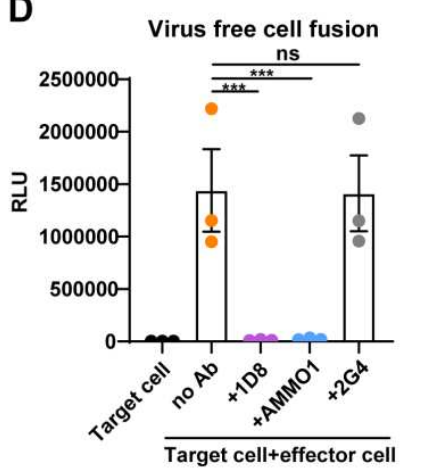

G

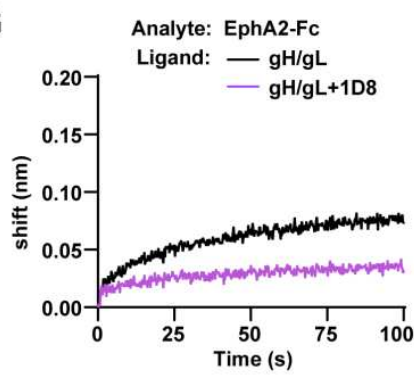

B

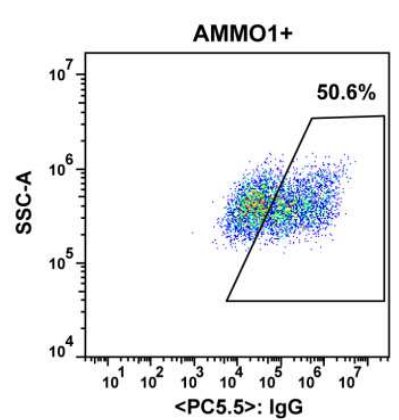

E
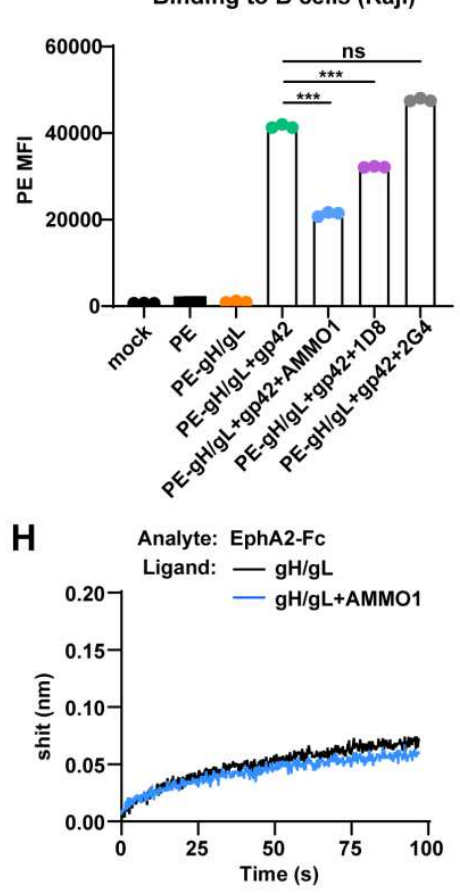

C

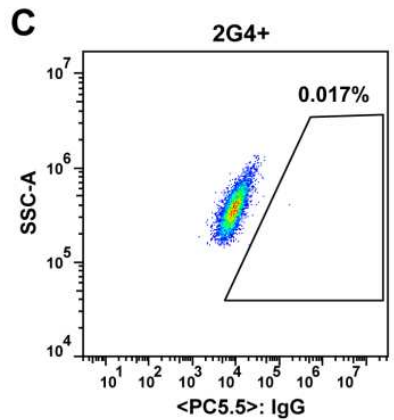

F Binding to epithelial cells (HK1)
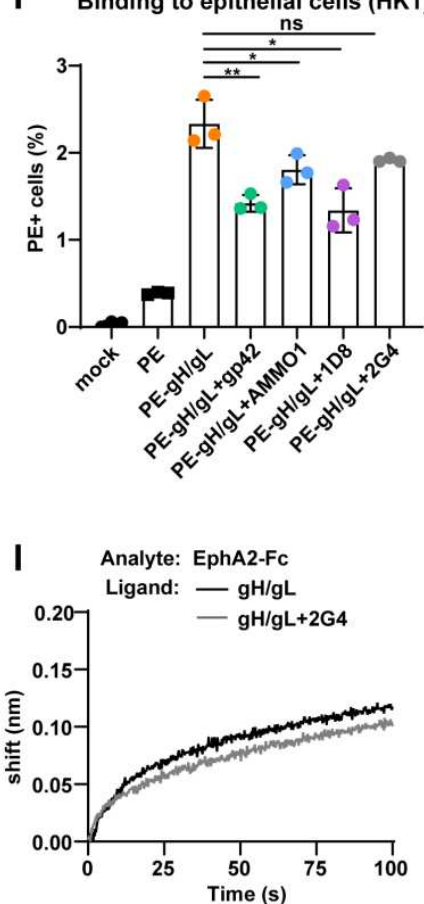
Fig. 6

A

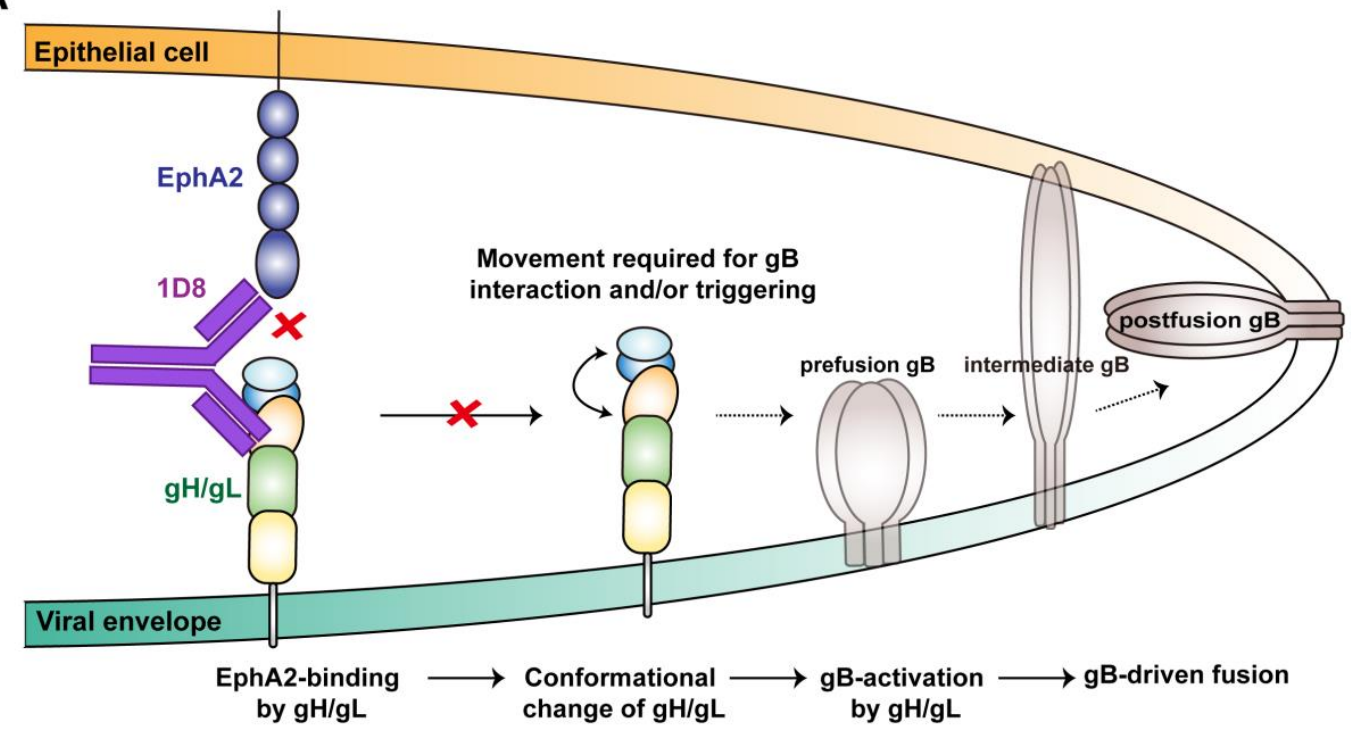

B

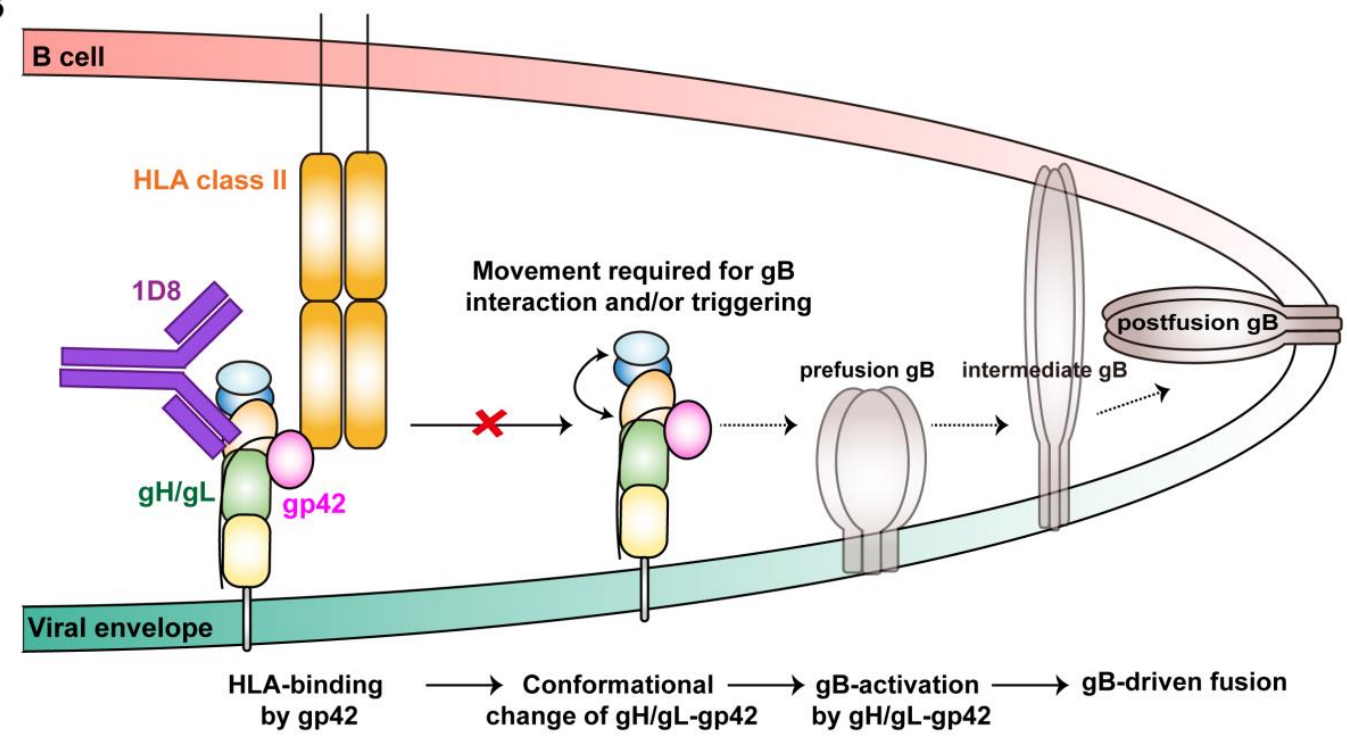



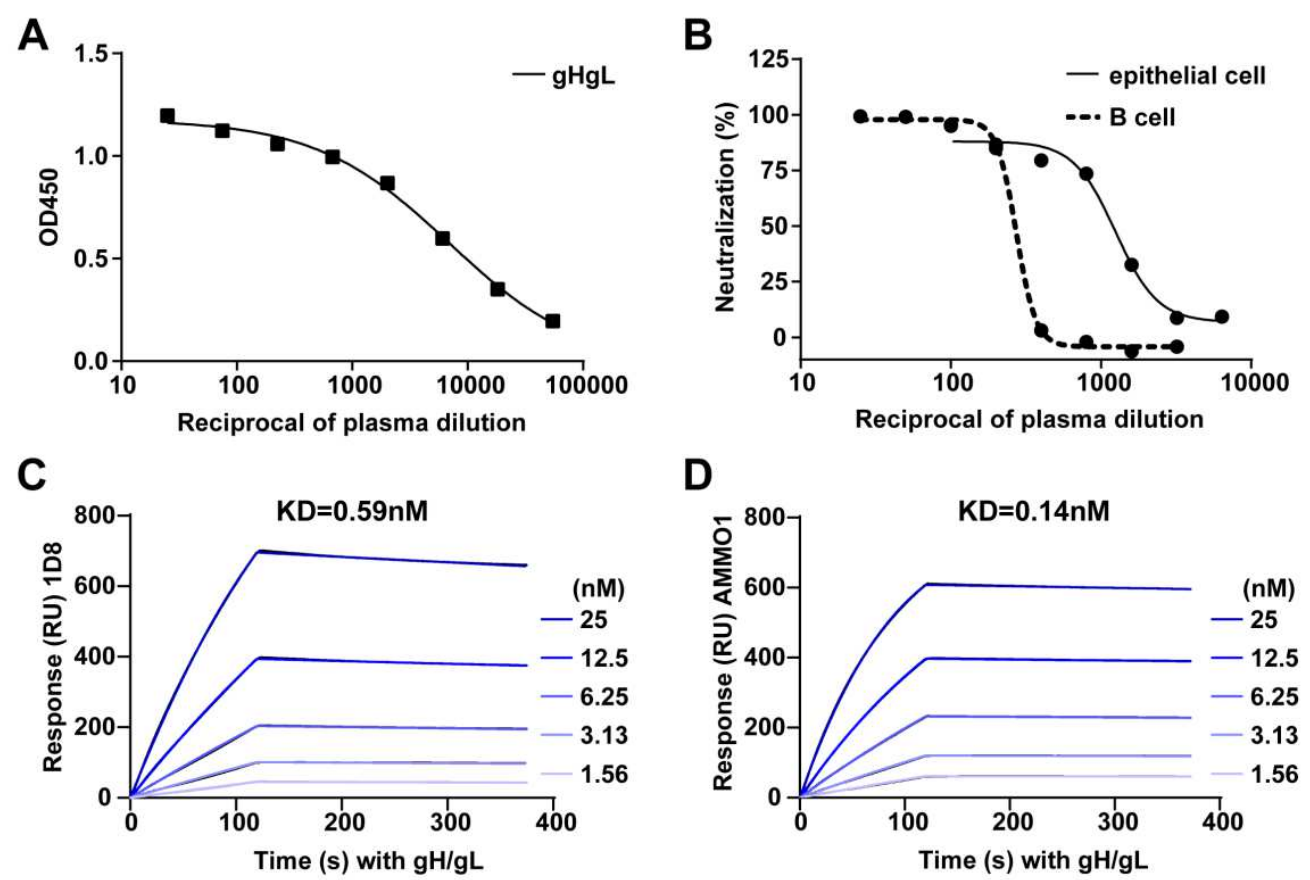

1022

Fig. S1. Plasma binding and neutralizing activities from donor 27.

(A) Plasma binding activities to $\mathrm{gH} / \mathrm{gL}$ measured by ELISA. (B) Plasma neutralizing activities against EBV infection of Raji B cells and HNE1 epithelial cells. Binding activity of 1D8 (C) or AMMO1 (D) to $\mathrm{gH} / \mathrm{gL}$ measured by surface plasmon resonance (SPR). All experiments were performed in duplicate, and the data shown are means with SEM. 

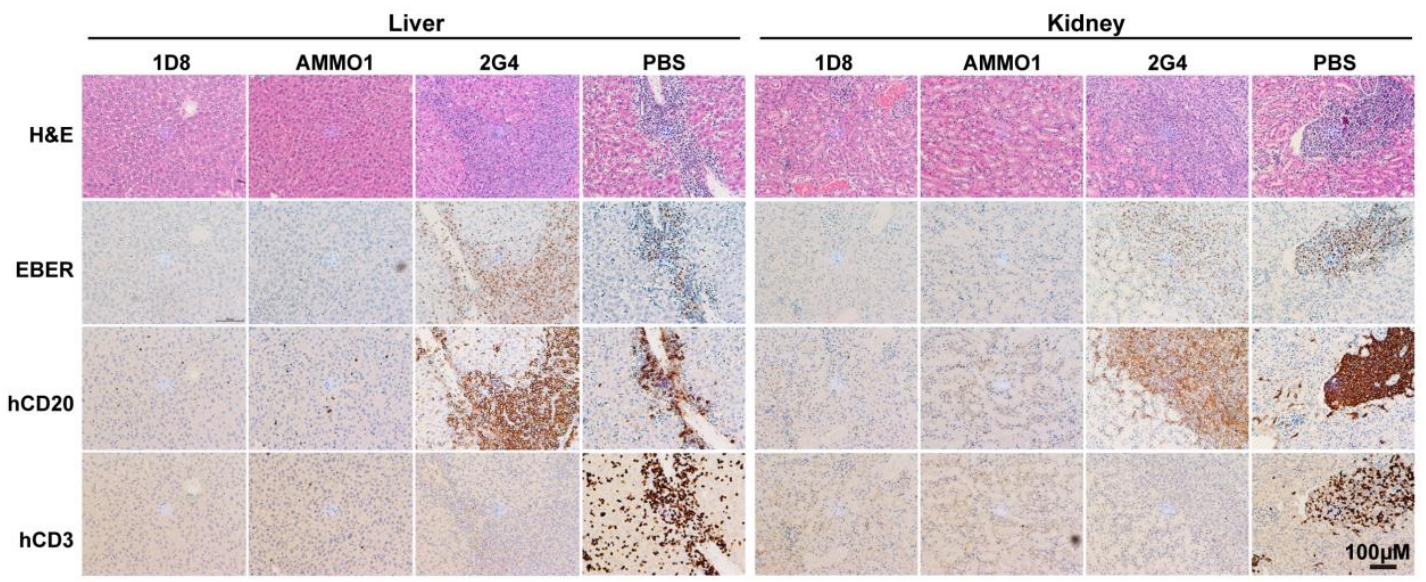

1033

Fig. S2. 1D8 reduces viral replication and tissue damages in liver and

kidney of mice.

Hepatic and renal sections stained for hematoxylin and eosin (H\&E), human

CD20 (hCD20), human CD3 (hCD3), and EBV encoded RNA (EBER) at necropsy. Scale bar of $100 \mu \mathrm{m}$ is shown. 
1049

1050

1051

1052

1053

1054

1055

1056

1057

1058

1059

1060

1061

1062

1063

1064

1065

1066

1067

1068

1069

1070

1071

1072

1073

1074

1075
A

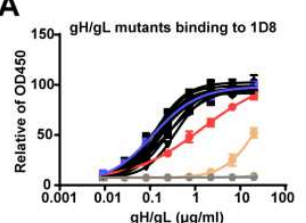

C

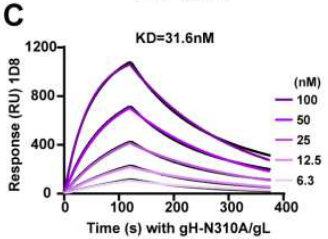

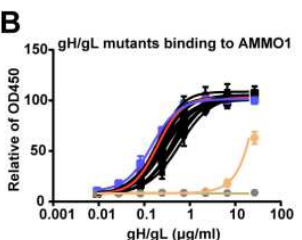

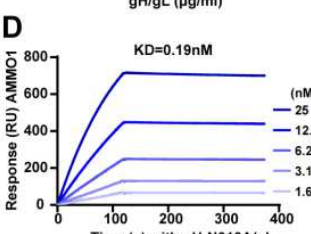

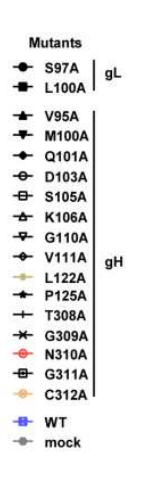

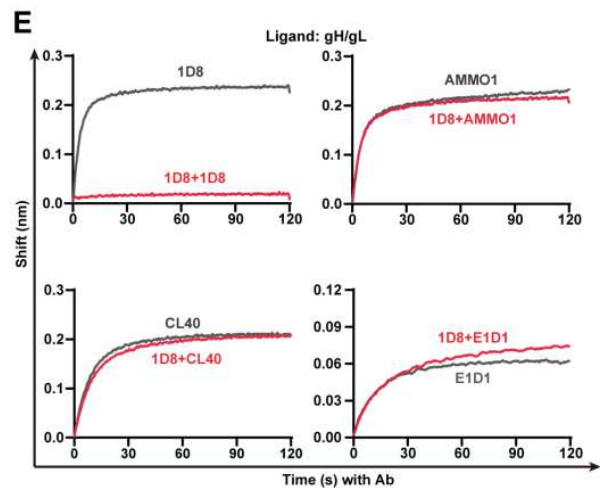

Fig. S3. Binding of $1 \mathrm{D} 8$ to $\mathrm{gH} / \mathrm{gL}$ mutants and its competition with other gH/gL antibodies.

(A) $1 \mathrm{D} 8$ and (B) AMMO1 binding to various $\mathrm{gH} / \mathrm{gL}$ mutants measured by ELISA. ELISA was performed in duplicate wells, and the data shown are means with SEM. Binding activity of 1D8 (C) and AMMO1 (D) to gH-N310A/gL mutant measured by surface plasmon resonance (SPR). (E) Competitive binding of 1D8 with AMMO1, CL40 or E1D1 to $\mathrm{gH} / \mathrm{gL}$ measured by bio-layer interferometry (BLI). 
1076 Table S1. Neutralization potency of monoclonal antibodies.

\begin{tabular}{ccccc}
\multirow{2}{*}{ Mab } & \multicolumn{2}{c}{ Epithelial cells $(\mu \mathrm{g} / \mathrm{ml})$} & \multicolumn{2}{c}{ B cells $(\mu \mathrm{g} / \mathrm{ml})$} \\
\cline { 2 - 5 } & $\mathrm{IC}_{50}$ & $\mathrm{IC}_{90}$ & $\mathrm{IC}_{50}$ & $\mathrm{IC}_{90}$ \\
\hline 1D8 & 0.123 & 0.187 & 0.238 & 0.442 \\
2A6 & 0.745 & 2.270 & 1.320 & $>50$ \\
AMMO1 & 0.127 & 0.305 & 0.318 & 1.148 \\
$2 \mathrm{G} 4$ & $\mathrm{NA}$ & $\mathrm{NA}$ & $\mathrm{NA}$ & $\mathrm{NA}$ \\
\hline
\end{tabular}

1077

1078

1079

1080

1081

1082

1083

1084

1085

1086

1087

1088

1089

1090

1091

1092

1093

1094 

SPR.

\begin{tabular}{|c|c|c|c|c|}
\hline Ligand & Anylate & kon $(1 / \mathrm{Ms}) \times 10^{5}$ & $\operatorname{koff}(1 / \mathrm{s}) \times 10^{-4}$ & $\mathrm{KD}(\mathrm{nM})$ \\
\hline 1D8 & $\mathrm{gH} / \mathrm{gL}$ S97A & 1.33 & 1.36 & 1.02 \\
\hline 1D8 & $\mathrm{gH} / \mathrm{gL}$ L100A & 1.07 & 1.55 & 1.44 \\
\hline 1D8 & $\mathrm{gH} V 95 \mathrm{~A} / \mathrm{gL}$ & 1.30 & 2.31 & 1.77 \\
\hline 1D8 & $\mathrm{gH}$ M100A/gL & 1.51 & 1.96 & 1.30 \\
\hline 1D8 & $\mathrm{gH} Q 101 \mathrm{~A} / \mathrm{gL}$ & 0.95 & 1.95 & 2.03 \\
\hline 1D8 & gH D103A/gL & 0.72 & 0.69 & 0.95 \\
\hline 1D8 & $\mathrm{gH} \mathrm{S} 105 \mathrm{~A} / \mathrm{gL}$ & 0.90 & 0.97 & 1.08 \\
\hline $1 \mathrm{D} 8$ & $\mathrm{gH} \mathrm{K106A/gL}$ & 1.26 & 1.09 & 0.86 \\
\hline 1D8 & $\mathrm{gH}$ G110A/gL & 2.66 & 0.26 & 0.10 \\
\hline 1D8 & $g \mathrm{H}$ V111A/gL & 1.11 & 1.48 & 1.34 \\
\hline $1 \mathrm{D} 8$ & $\mathrm{gH}$ P125A/gL & 0.71 & 2.00 & 2.79 \\
\hline 1D8 & $\mathrm{gH}$ T308A/gL & 1.04 & 1.01 & 0.97 \\
\hline 1D8 & gH G309A/gL & 0.95 & 0.95 & 1.00 \\
\hline 1D8 & $\mathrm{gH}$ N310A/gL & 1.75 & 55.20 & 31.60 \\
\hline 1D8 & $\mathrm{gH}$ G311A/gL & 0.78 & 2.05 & 2.62 \\
\hline 1D8 & gH/gL WT & 2.45 & 1.46 & 0.59 \\
\hline AMMO1 & $\mathrm{gH}$ N310A/gL & 4.97 & 0.96 & 0.19 \\
\hline AMMO1 & gH/gL WT & 5.77 & 0.85 & 0.14 \\
\hline
\end{tabular}


Table S3. Data collection and refinement statistics.

\section{EBV $\mathrm{gH} / \mathrm{gL}-1 \mathrm{D} 8$}

\section{Data collection}

Space group

Cell dimensions

$$
\begin{aligned}
& a, b, c(\AA) \\
& \alpha, \beta, \gamma,\left(^{\circ}\right)
\end{aligned}
$$

Resolution $(\AA)$

$R_{\text {sym }}$ or $R_{\text {merge }}$

I/s/

Completeness (\%)

Redundancy

\section{Refinement}

Resolution $(\AA)$

No. reflections

$R_{\text {work }} / R_{\text {free }}$

No. atoms

Protein

$B$-factors

Protein

R.m.s. deviations

$$
\begin{array}{ll}
\text { Bond lengths }(\AA) & 0.009 \\
\text { Bond angles }\left({ }^{\circ}\right) & 1.98
\end{array}
$$

Ramachandran plot (\%)

Favored

$91.48 \%$

Allowed

\section{$7.06 \%$}

outlier

One crystal was used.

*Values in parentheses are for highest-resolution shell. 

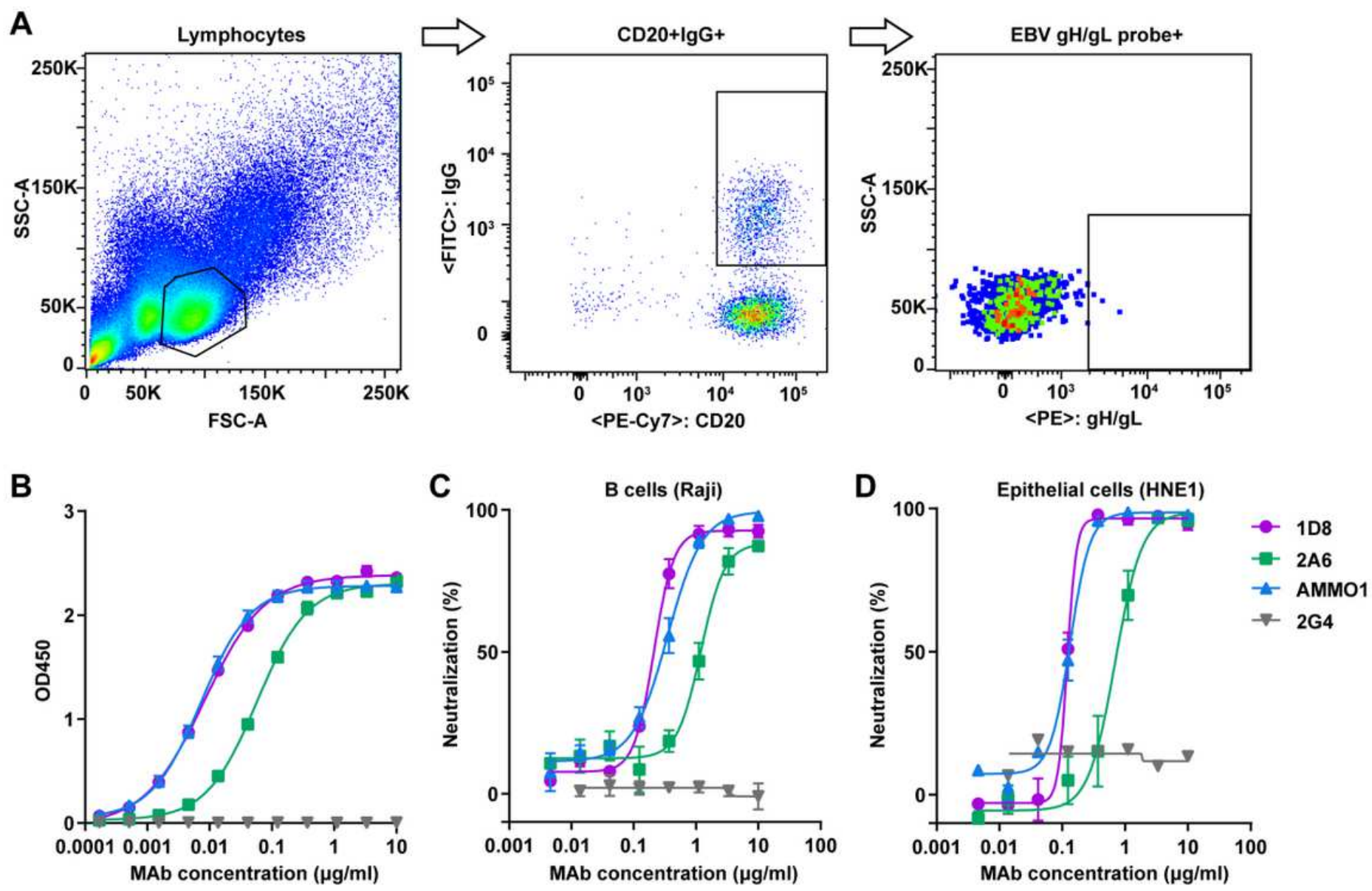

\section{Figure 1}

Isolation of $\mathrm{gH} / \mathrm{gL}$ specific monoclonal antibodies using single B cell sorting and cloning A FACS based sorting strategy for $\mathrm{gH} / \mathrm{gL}$ specific $B$ cells. B Binding activities of 1D8 and 2A6, the positive control AMM01, and the negative control $2 \mathrm{G} 4$ to EBV $\mathrm{gH} / \mathrm{gL}$ measured by ELISA. The data are presented as means \pm SEM. C Neutralizing activities of $1 \mathrm{D} 8$ and 2A6, the positive control AMM01, and the negative control 2G4 against EBV infection of Raji B cell lines and D HNE1 epithelia cell line. The data shown is means \pm SEM. SSC A, side scatter area; FSC A, forward scatter area. 


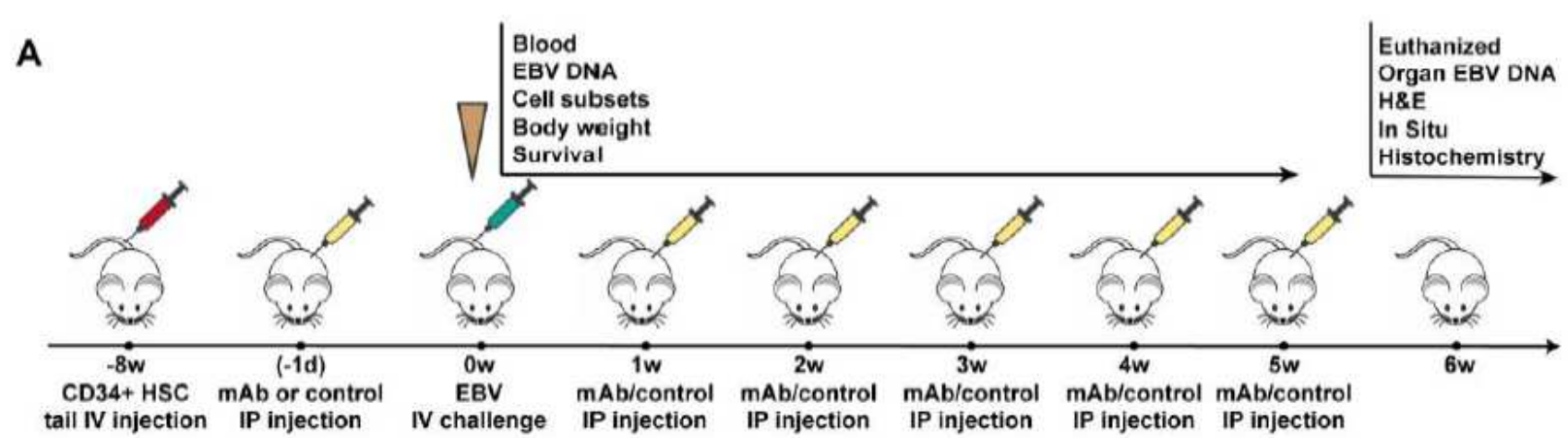

B

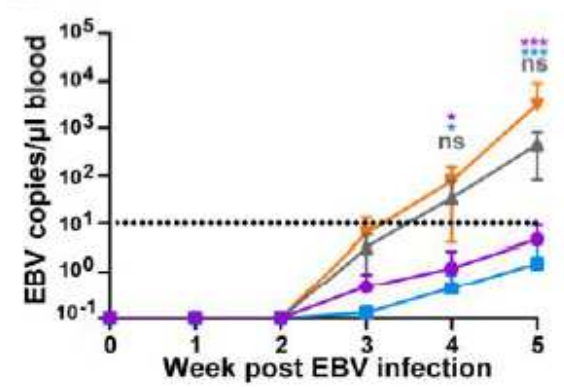

E

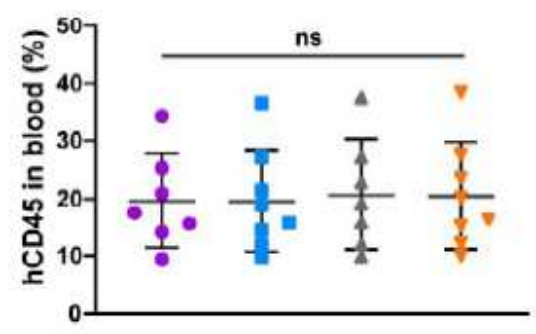

H

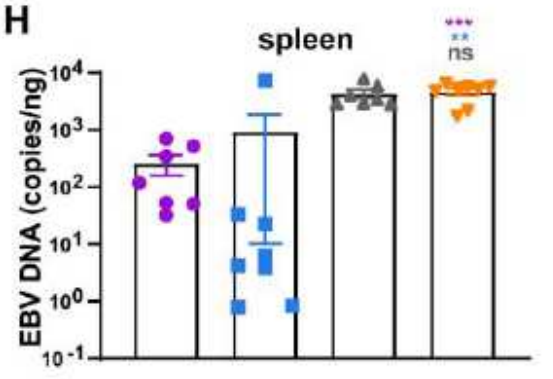

C

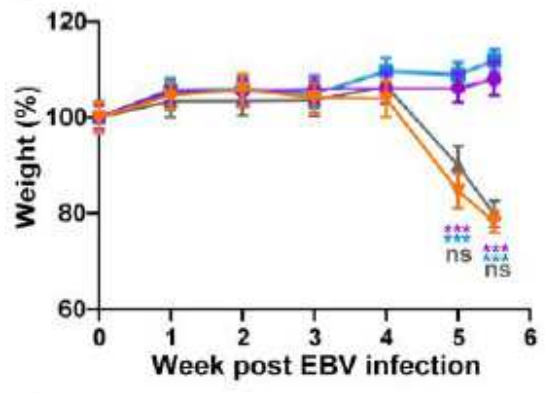

$\mathbf{F}$
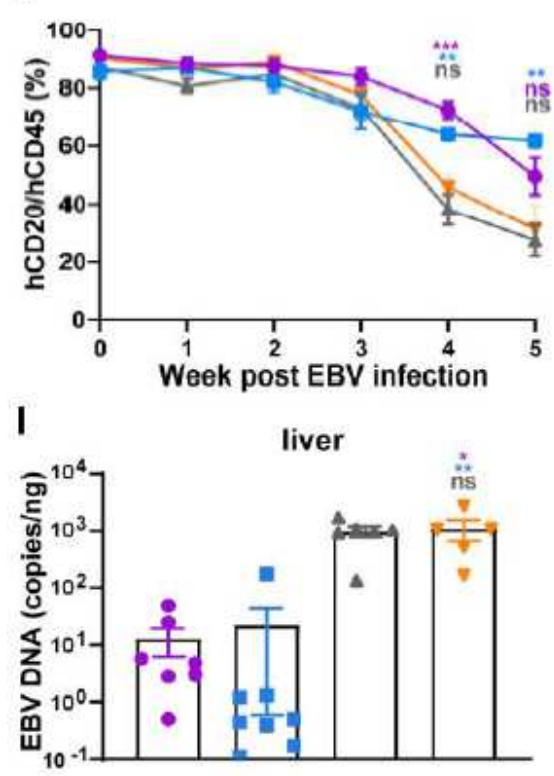

D

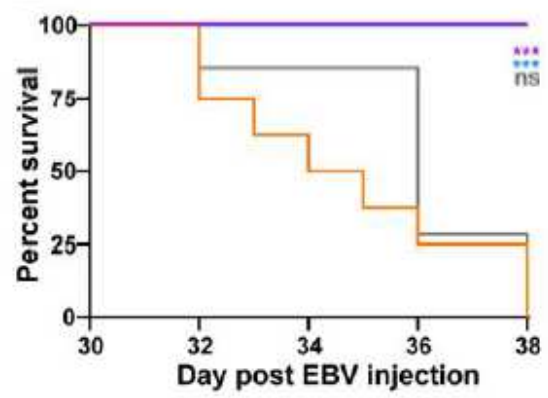

G
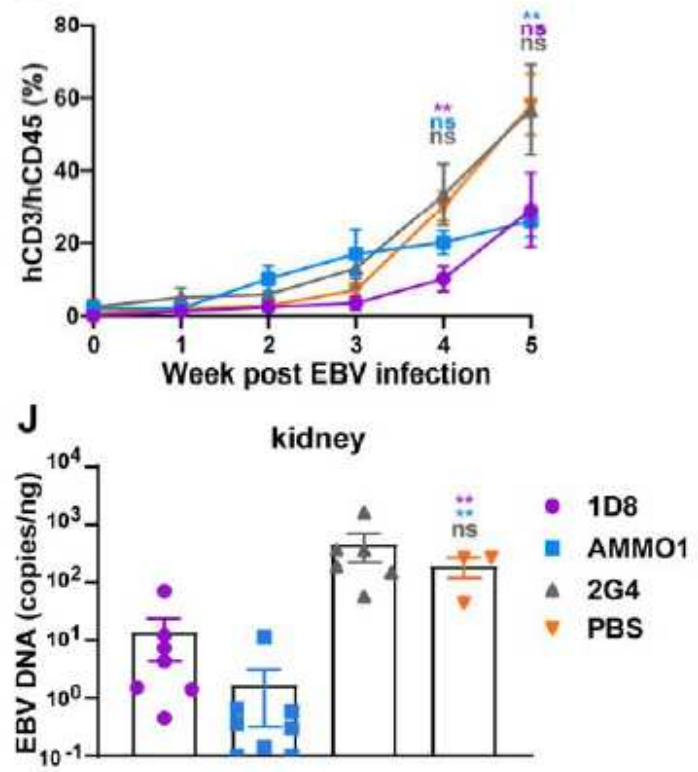

Figure 2

Protective effi cacy of 1D8 against lethal EBV challenge in humanized mice A Timeline for engrafting CD34+ human hematopoietic stem cells (HSC), antibody administration, viral challenge, and monitoring for various biological and clinical outcomes. Four hundred micrograms of 1D8, positive control AMM01, negative control $2 \mathrm{G} 4$, or PBS negative control were administered to the humanized mice via intraperitoneal injection either $24 \mathrm{~h}$ prior to or weekly for 5 weeks after intravenous challenge with Akata EBV. ( B ) EBV DNA in the peripheral blood, ( C ) body weight, and D ) survival were monito red weekly. The percent changes in (E) hCD45+, F) hCD20+, or G ) hCD3+ cells over the experiment period. On week 6 post infection, $(\mathrm{H})$ virus titers in spleen, $(\mathrm{I})$ liver, $\mathrm{J}$ ) kidney were analyzed. All data are presented as mean \pm SEM. ${ }^{*} p<0.05 ;{ }^{* \star} p<0.01 ; * \star * p<0.001 ; n s$, no significant. 


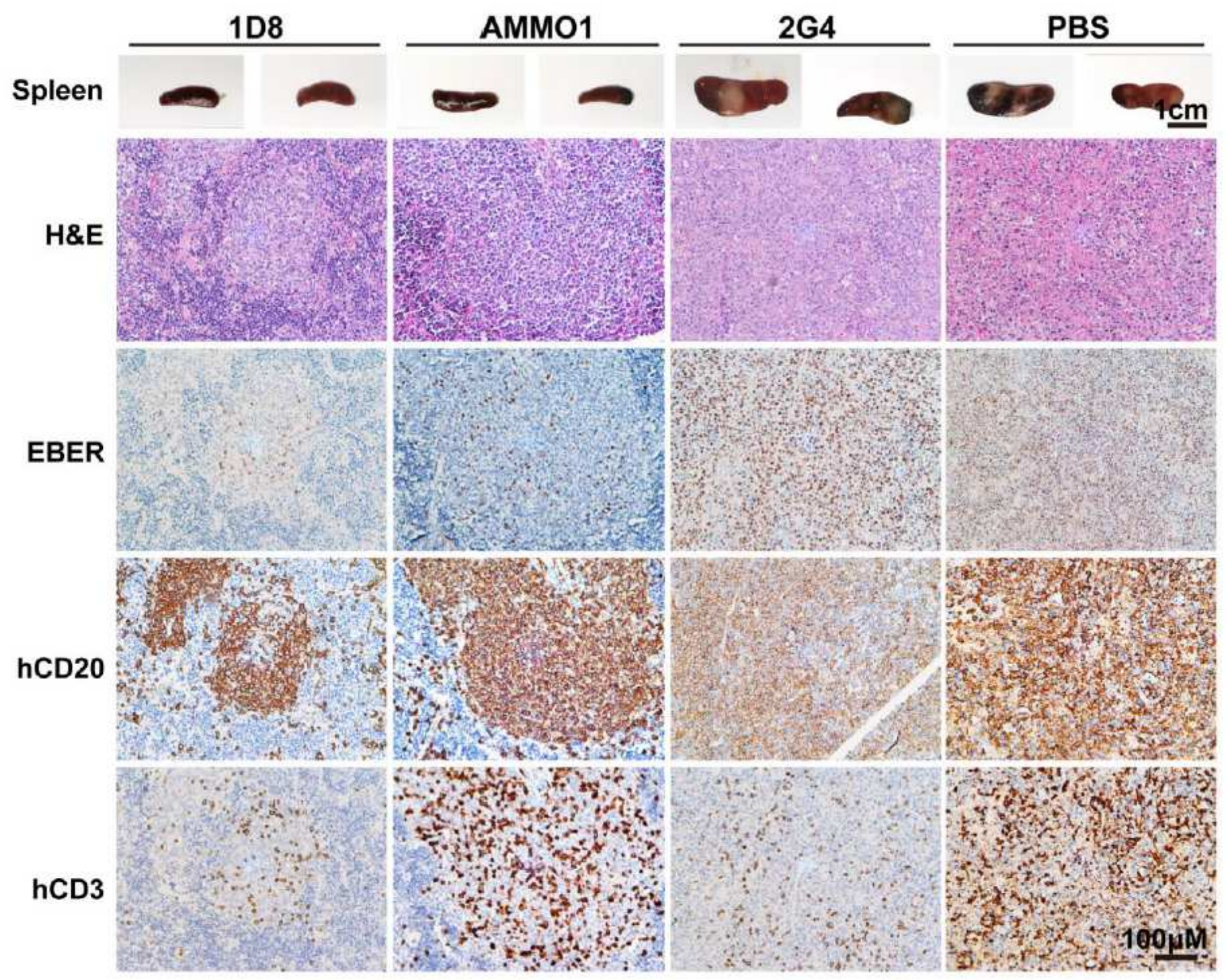

Figure 3

1D8 reduces viral replication and tissue damages in humanized mice Representative of macroscopic spleens and splenic sections stained for hematoxylin and eosin (H\&E), EBV encoded RNA (EBER), human CD20 ( and human CD3 (hCD3) at necropsy. The scale bars are indicated. 

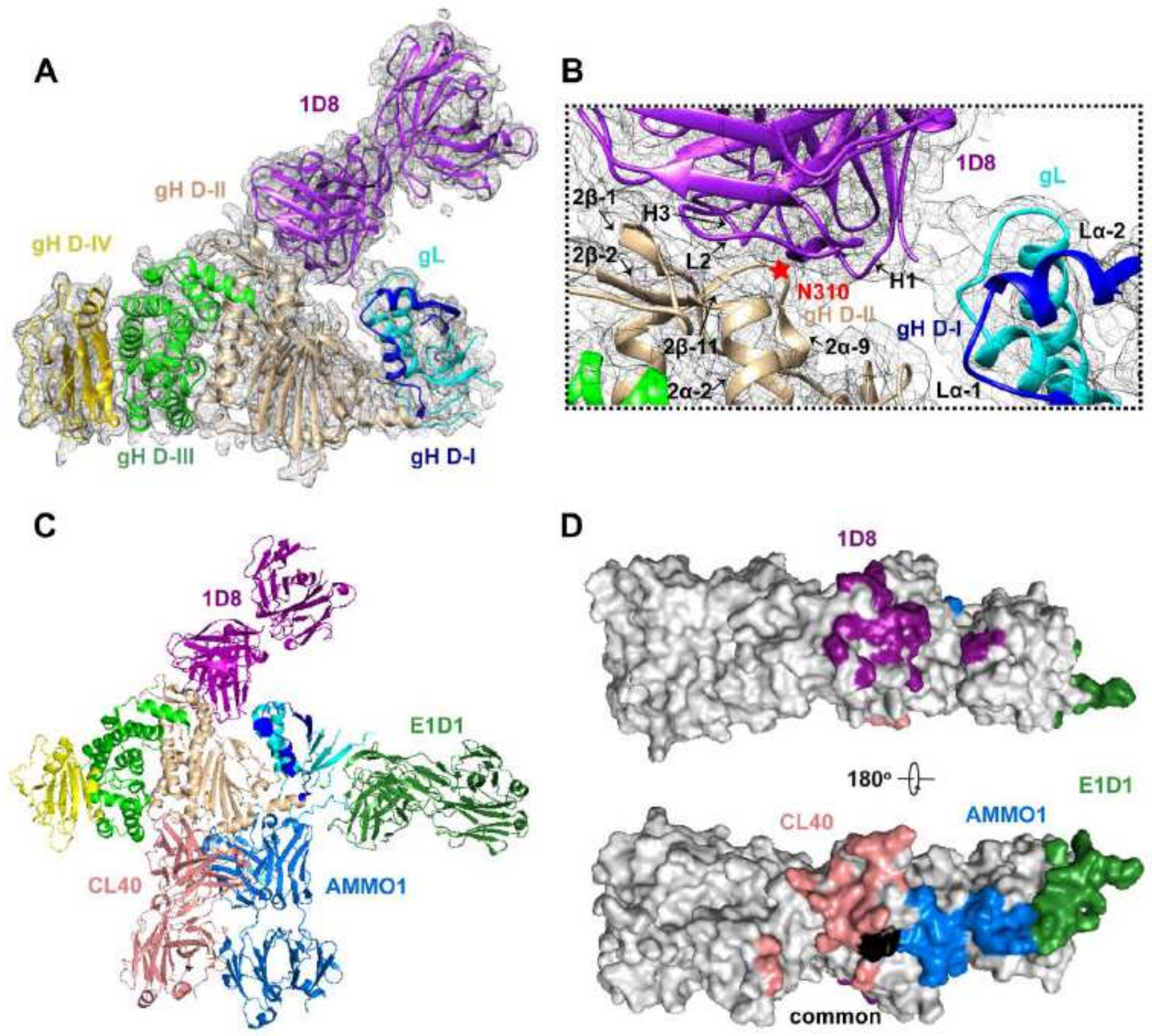

\section{Figure 4}

1D8 targets an unique epitope on $\mathrm{gH} / \mathrm{gL}$ A Structure overview in a cartoon representation with $\mathrm{gL}$ in cyan, gH D I in blue, D II in wheat, D III in green, D IV in yellow, and 1D8 Fa b in purple. The map is contoured at 1.2 RMS to show the density. B Zoomed in view of the interaction between $1 \mathrm{D} 8$ and D I and D II. The key binding residue $\mathrm{N} 310$ of $\mathrm{gH}$ was indicated by a red star. $\mathrm{C}$ Cartoon representation of Fab 1D8 and other previously published Fabs AMM01, CL40, and E1D1 bound to a single $\mathrm{gH} / \mathrm{gL}$ molecule. The color scheme for $\mathrm{gH} / \mathrm{gL}$ is as in ( A ) whereas 1D8 Fab in purple, AMM01 Fab in light blue, CL40 Fab in pink, and E1D1 Fab in dar k green. D Surface mapping of the four Fab epitopes on $\mathrm{gH} / \mathrm{gL}$ with the same color in $\mathrm{C}$ )). Areas in black indicate the region where structural change was found upon binding to AMMO1 or CL40. 
A

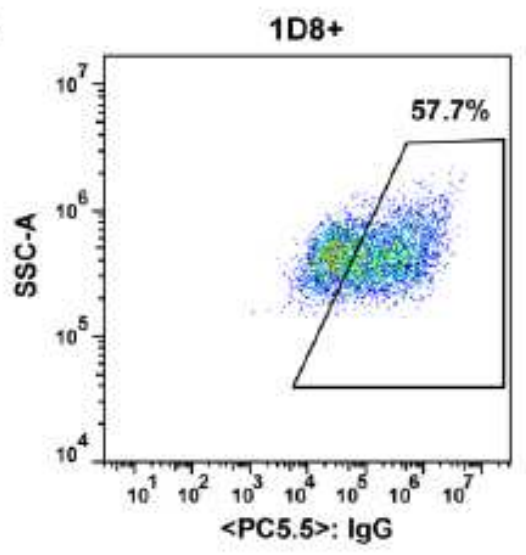

D

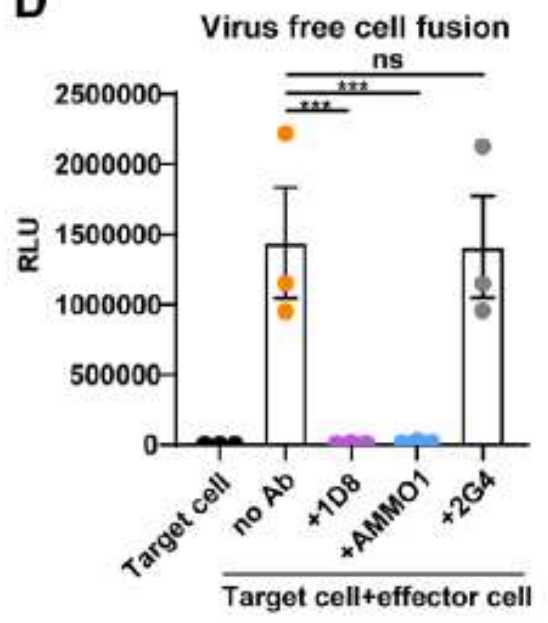

G

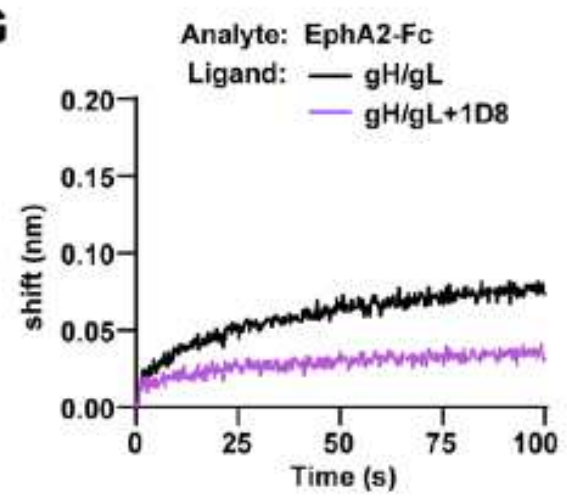

B

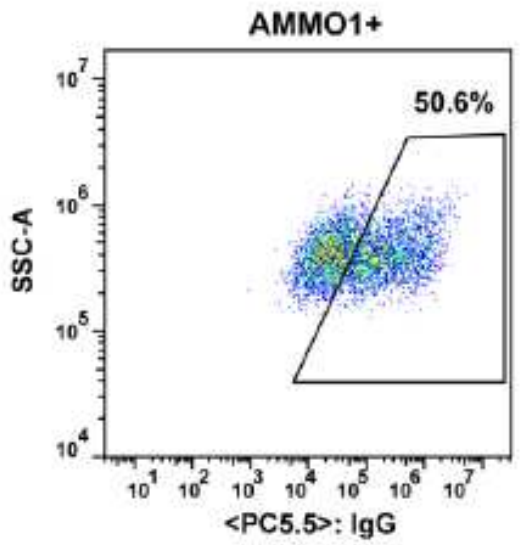

E
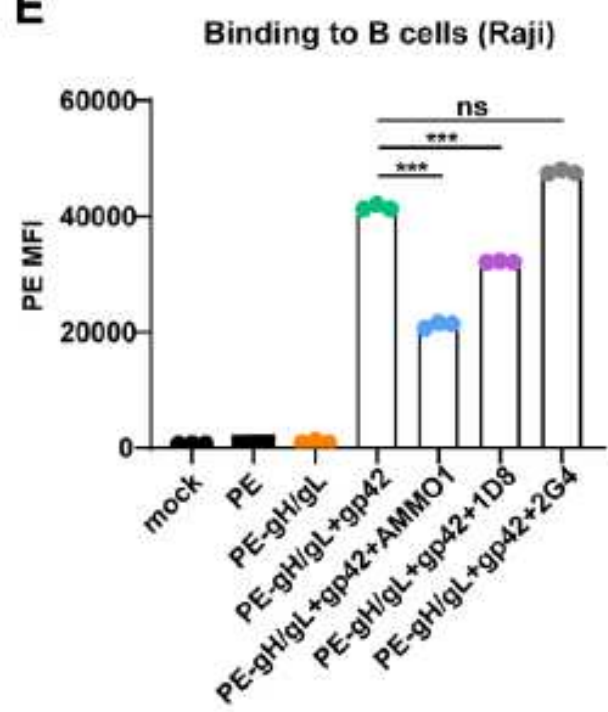

H

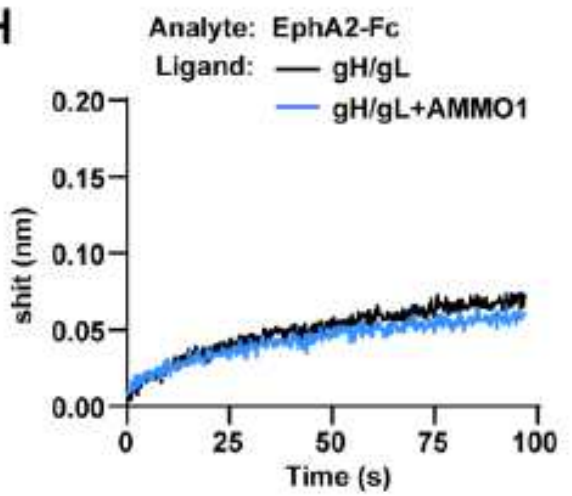

C

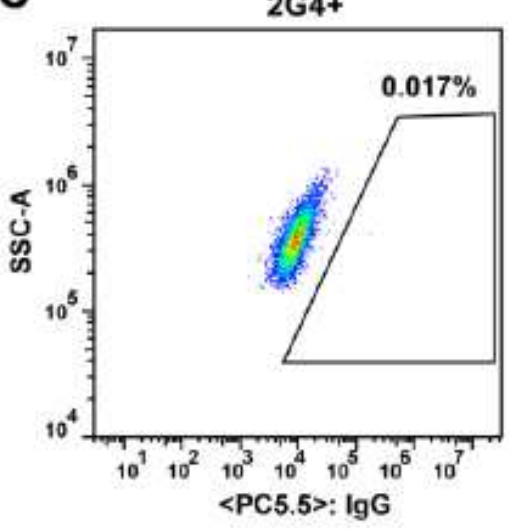

F Binding to epithelial cells (HK1)
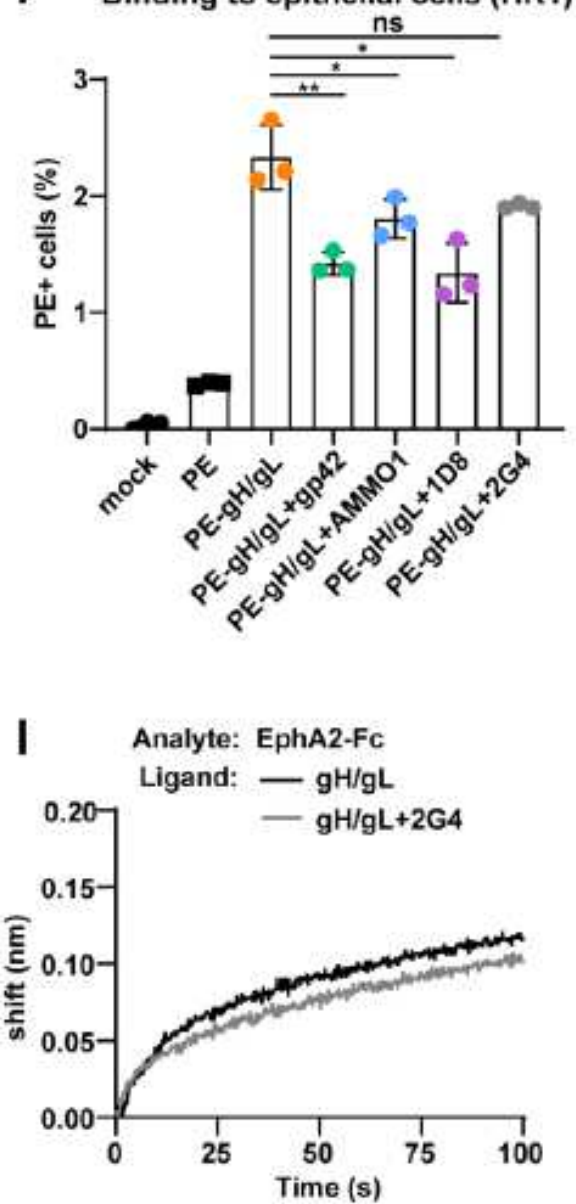

\section{Figure 5}

1D8 interferes with cell fusion and binding Quality control of $\mathrm{gH} / \mathrm{gL}$ expression on the surface of $\mathrm{CHO} \mathrm{K} 1$ cells by staining with 1D8 (A), positive control AMM01 (B), and negative control 2G4 (C) before proceeded to the fusion experiment shown in (D). (D) Marked reduction in cell cell-cell fusion in the presence of 1D8, the positive control AMMM01, but not the negative control 2G4. Marked reduction in $\mathrm{gH} / \mathrm{gL}$ binding to Raji B cell (E) and HK1 epithelial cell $(F)$ in the presence of $1 \mathrm{D} 8$, the positive control AM $\mathrm{MO1}$, but not the negative control 2G4. Binding of EphA1 EphA1-Fc to $\mathrm{gH} / \mathrm{gL}$ was reduced by 1D8 ( $\mathrm{G})$, but not by $\mathrm{AMMO1}(\mathrm{H})$ or $2 \mathrm{G} 4 \mathrm{I})$ measured by Bio Bio-layer interferometry (BLI). All data are presented as 
mean \pm SEM. ${ }^{*} \mathrm{p}<0.05 ;{ }^{* \star} \mathrm{p}<0.01 ;{ }^{* \star \star} \mathrm{p}<0.001 ; \mathrm{ns}$, no significant. SSC SSC-A, side side-scatter area; PC5.5, PerCP PerCP-Cy5.5; RLU, relative light unit; SA SA-PE, streptavidin streptavidin-phycoerythrin; MFI, mean fluorescence intensity.

A

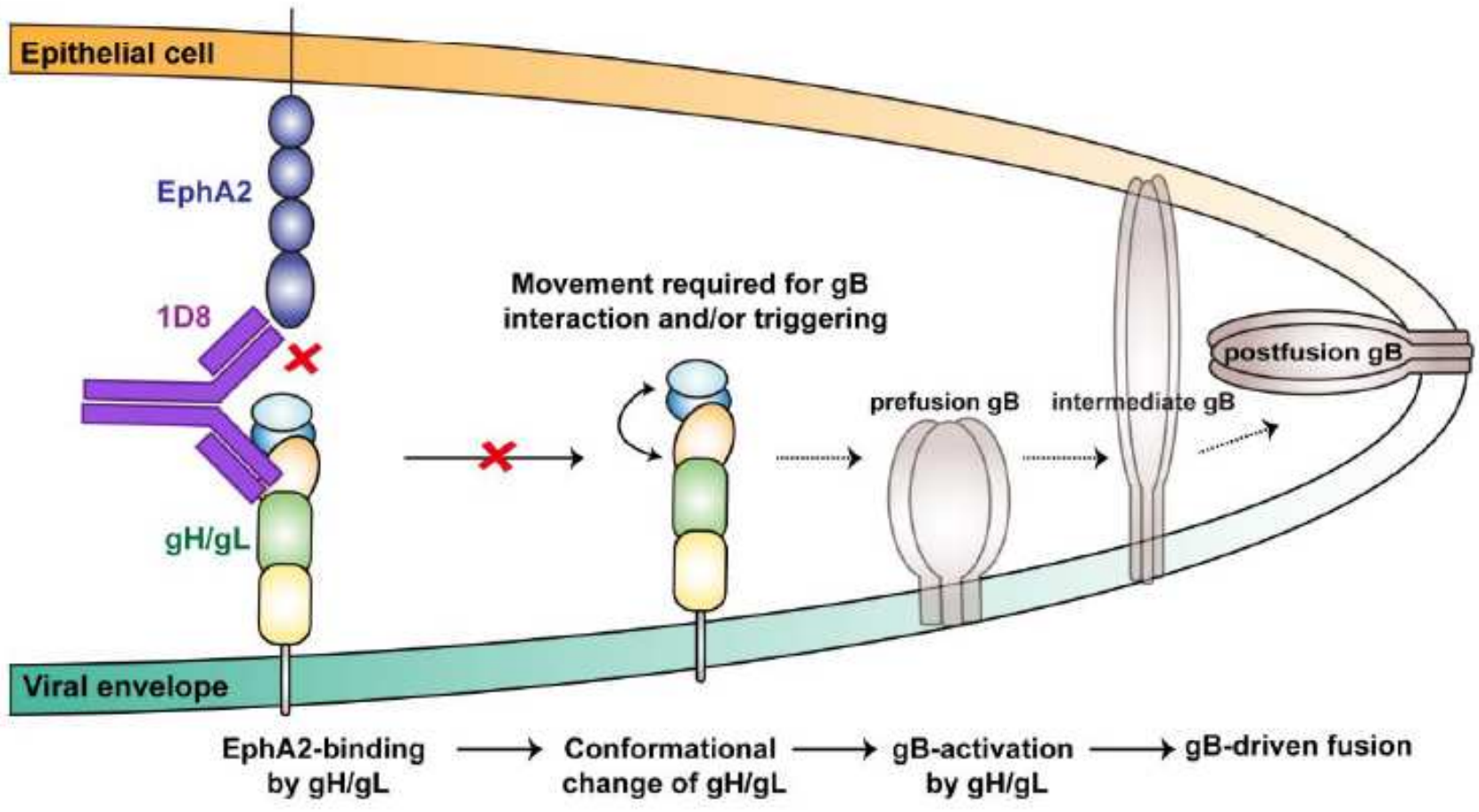

B

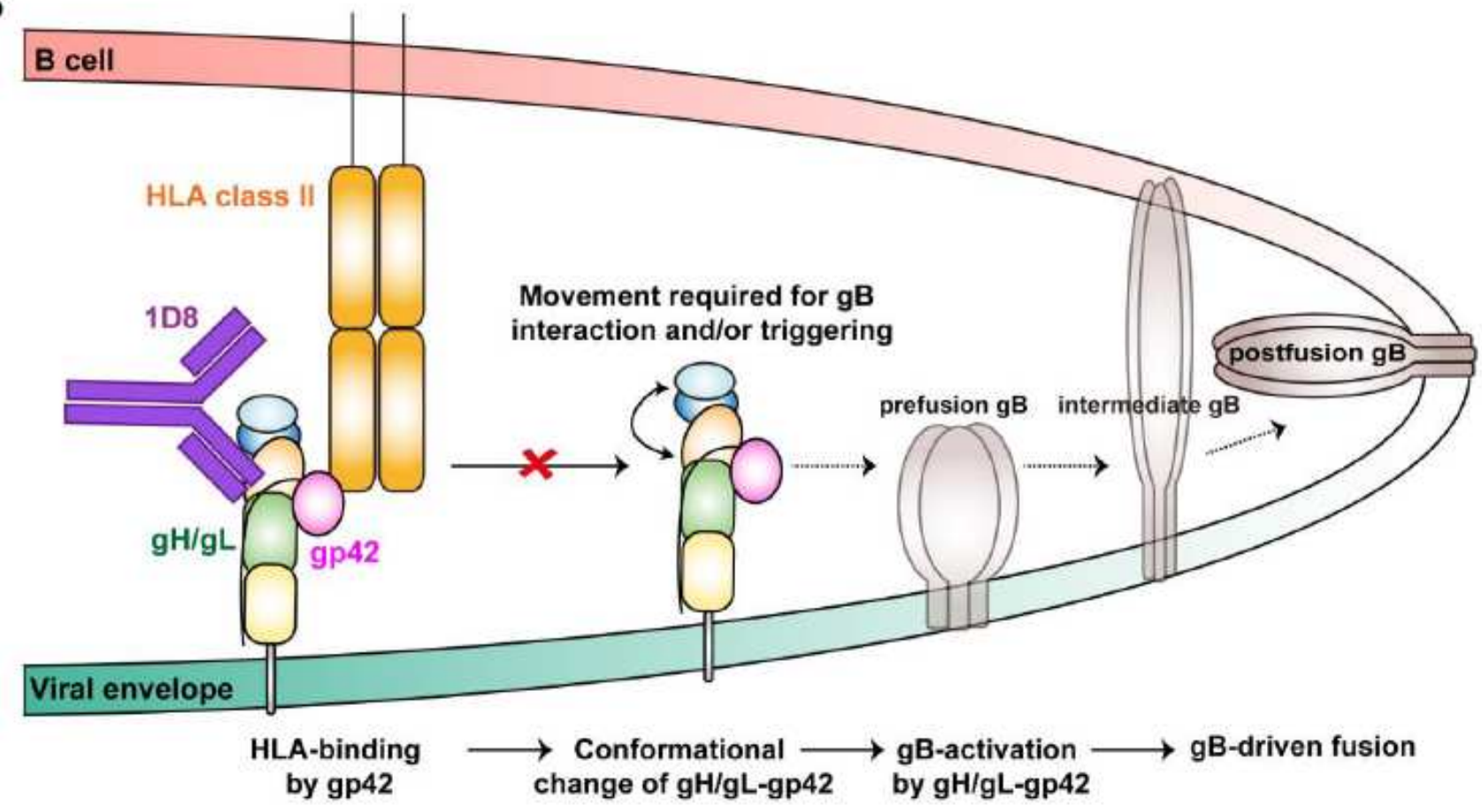

Figure 6

Possible mechanisms of 1D8 1D8-mediated neutralization neutralization. (A) For epithelia cells, 1D8 could interfere the interaction between $\mathrm{gH} / \mathrm{gL}$ and $\mathrm{EphA} 2$ either by directly restricting access to the 
interface or by indirectly posing allosteric hindrance. It could also restrict the movement across the D D$\mathrm{l} / \mathrm{D}-\mathrm{Il}$ groove of $\mathrm{gH} / \mathrm{gL}$ that is required for $\mathrm{gB}$ interaction and triggering. (B) For B cells, 1D8 could also restrict the movement across the $\mathrm{D} D-\mathrm{I} / \mathrm{D}$-II groove of $\mathrm{gH} / \mathrm{gL}$ that is required for downstream viral entry. 1D8 does not appear influence interaction between gp42 and its recepto $r$ HLA class II. 